\title{
ResearchOnline@JCU
}

This is the author-created version of the following work:

Floeter, Sergio R., Bender, Mariana G., Siqueira, Alexandre C., and Cowman, Peter F. (2018) Phylogenetic perspectives on reef fish functional traits. Biological Reviews, 93 (1) pp. 131-151.

Access to this file is available from:

https://researchonline.jcu.edu.au/48852/

Please refer to the original source for the final version of this work:

http://dx.doi.org/10.1111/brv.12336 


\section{Phylogenetic perspectives on reef fish functional traits}

2

3 Sergio R. Floeter ${ }^{1, *}$, Mariana G. Bender ${ }^{1}$, Alexandre C. Siqueira ${ }^{1}$ and Peter

4 F. Cowman 2,3

5

6

${ }^{1}$ Marine Macroecology and Biogeography Lab., CCB, Universidade Federal de Santa Catarina, Florianopolis, Brazil, 88040-900

${ }^{2}$ Department of Ecology and Evolutionary Biology, Yale University, New Haven, CT, USA, 06511 ${ }^{3}$ ARC Centre of Excellence for Coral Reef Studies, James Cook University, Townsville, Queensland, Australia, 4811

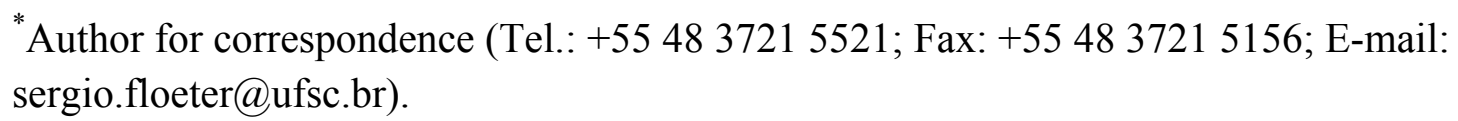

\section{ABSTRACT}

Functional traits have been fundamental to the evolution and diversification of entire fish lineages on coral reefs. Yet their relationship with the processes promoting speciation, extinction and the filtering of local species pools remains unclear. We review the current literature exploring the evolution of diet, body size, water column use and geographic range size in reef-associated fishes. Using published and new data, we mapped functional traits on to published phylogenetic trees to uncover evolutionary patterns that have led to the current functional diversity of fishes on coral reefs. When examining reconstructed patterns for diet and feeding mode, we found examples of independent transitions to planktivory across different reef fish families. Such transitions and associated morphological alterations may represent cases in which ecological opportunity for the exploitation of different resources drives speciation and adaptation. In terms of body size, reconstructions showed that both large and small sizes appear multiple times within clades of mid-sized fishes and that extreme body sizes have arisen mostly in the last 10 million years (Myr). The reconstruction of range size revealed many cases of disparate range sizes among sister species. Such range size disparity highlights potential vicariant processes through isolation in peripheral locations. When accounting for peripheral speciation processes in sister pairs, we found a significant relationship between labrid range size and lineage age. The diversity and evolution of traits within lineages is influenced by trait-environment interactions as well as by species and trait-trait interactions, where the presence of a given trait may trigger the development of related traits or behaviours. Our effort to assess the evolution of functional diversity across reef fish clades adds to the burgeoning research focusing on the evolutionary and ecological roles of functional traits. We argue that the combination of a phylogenetic and a functional approach will improve the 
understanding of the mechanisms of species assembly in extraordinarily rich coral reef communities.

Key words: diversification, coral reef, evolution, body size, life-history traits, planktivory, range size, reef fish ecology.

\section{CONTENTS}

I. Introduction . . . . . . . . . . . . . . . . . . . . . . . . . . . . . 02

II. The evolution of feeding modes of reef fishes . . . . . . . . . . . . . . 04

III. Water column use and shifts to planktivory. ................... 09

IV. The evolution of body size in reef fishes. . . . . . . . . . . . . . . . 12

V. Habitat use, range sizes and biogeography of reef fishes. . . . . . . . . . 13

(1) Habitat use. . . . . . . . . . . . . . . . . . . . . . . . 13

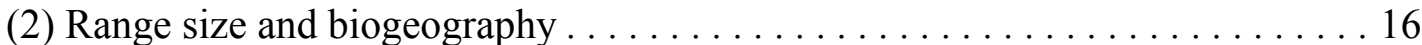

VI. Functional evolution of reef fish assemblages.................... 18

(1) Multi-trait comparisons, lineage accumulation and disparity through time .... 18

(2) A phylogenetic and functional approach to community assessment ....... 20

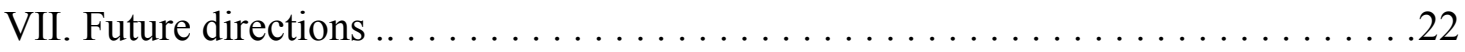

VIII. Conclusions. . . . . . . . . . . . . . . . . . . . . . . . . . . . . . . 24

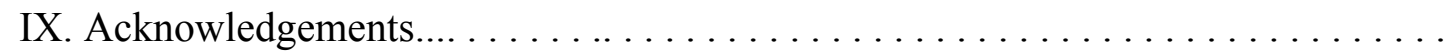
25

X. References........................................... 25

\section{INTRODUCTION}

Traits can be defined as any morphological, physiological, or phenological feature usually measurable at the individual level of a species. Such features arise in lineages through evolutionary time, usually being shared by species that have a recent common ancestry (Webb et al., 2002; Peres-Neto, 2004; Swenson et al., 2006; Kraft et al., 2007). On an ecological timescale, traits can mediate species interactions, thus influencing the distribution of organisms and the structure of local communities. The interactions among species are trait-mediated and have the potential to affect evolutionary processes, which in turn act upon species' ecological roles and the diversity of traits available in the regional pool (Cavender-Bares et al., 2009). In this way, species traits form a link between phylogenetic history (evolution and evolutionary time) and ecological processes.

Functional traits are defined as properties of an organism that influence their ecological and evolutionary performances in nature (Tilman, 2001; McGill et al., 2006; Violle et al., 2007; Mouillot et al., 2013). These organismal traits are used as currency in the comparisons made among sets of species, often as a measure of functional 
diversity (Walker, Kinzig \& Langridge, 1999; Tilman, 2001; McGill et al., 2006). Since traits affect ecosystem processes, a functional approach to studying biodiversity is essential to further our understanding of mechanisms and historical-evolutionary processes that have shaped current patterns of biodiversity (Loreau et al., 2001; Hooper et al., 2002; McGill et al., 2006). Most advances in understanding the evolution of functional traits and the mechanisms of species (and trait) assembly have come from studies conducted in terrestrial communities, particularly plant communities (Webb, 2000; Webb et al., 2002; Reich et al., 2003; Ackerly, 2009). The study of plant ecology and evolution has set the basis for the relationship between diversity and ecosystem functioning (Tilman et al., 1997; Tilman, 2001), the measure of functional attributes (Diaz, Cabido \& Casanoves, 1998; Westoby \& Wright, 2006), the concept of traits (Violle et al., 2007) and the mechanisms of local species pools and trait assembly (Webb, 2000; Webb et al., 2002; Ackerly, 2009). In the sea, only a handful of studies have examined the evolution of functional traits through time (Vermeij, 1977; Jablonski \& Sepkoski, 1996), mostly for assemblages inhabiting coral reefs (e.g. Wood, 1999; Goatley, Bellwood \& Bellwood, 2010; Bellwood, Goatley \& Bellwood, 2016). For fish species, life-history traits linked to food acquisition and locomotion mediate species ecological roles and influence ecosystems processes (Winemiller, 1991; Holmlund \& Hammer, 1999; Mouillot et al., 2013, 2014; Winemiller et al., 2015). Fish traits have also been fundamental to the evolution and diversification of entire fish lineages on coral reefs (Cowman, Bellwood \& van Herwerden, 2009; Price et al., 2011). Although coral reefs present an extremely rich fish assemblage with at least 50 evolutionary transitions to reef-dwelling within Acanthomorpha (spiny-rayfinned fishes) alone (Price et al., 2014), some families (e.g. butterflyfishes - Chaetodontidae, wrasses and parrotfishes - Labridae, surgeonfishes - Acanthuridae, angelfishes Pomacanthidae, damselfishes - Pomacentridae, cardinalfishes - Apogonidae) are considered typical 'reef' fish families with most species being dependent on coral reef environments across the globe (e.g. Bellwood, 1996; Cowman, 2014). Several of these families have formed the core focus of recent studies that characterize how particular species traits map onto a reconstructed phylogenetic hypothesis (e.g. Bellwood et al., 2010; Price et al., 2011; Frédérich et al., 2013; Lobato et al., 2014), and how they correlate with the observable evolutionary history of a group of species. However, it remains unclear whether any of these traits can be linked to the processes promoting speciation, extinction, or the assembly of local species pools. Here we use new and 
updated life-history trait reconstructions of some of these core reef-associated fish families, as well as re-analyses of published reconstructions, better to understand evolutionary patterns that have led to the functional diversity found on coral reefs today. We further discuss patterns reported in other fish families found on coral reefs that might be influenced by different evolutionary processes but for which we have less information. We provide future directions to this emerging field of functional phylogenetics. Moving forward, a combination of phylogenetic and functional assessment methods will improve our understanding of the mechanisms that shape species assemblages, particularly the extraordinarily rich communities associated with coral reefs.

\section{THE EVOLUTION OF FEEDING MODES OF REEF FISHES}

The evolution of feeding modes has been an important topic in the origins of modern coral reef assemblages (Bellwood et al., 2015). The distinctness of a 'reef-like' assemblage in the fossil record is not only signalled by the taxonomic make-up of a lagerstätten (Bellwood, 1996), but also by the functional attributes of fossils (Goatley et al., 2010; Bellwood et al., 2014b). Particularly interesting are those that indicate the presence of potentially herbivorous taxa (Bellwood et al., 2014a), precursor lineages to modern herbivores and detritivores that provide critical functions on modern coral reefs (Hoey \& Bellwood, 2008; Bonaldo, Hoey \& Bellwood, 2014). Traditionally, the groups that are presently the most conspicuous and abundant in reef habitats have well-resolved (but still incomplete) dated phylogenies and have garnered the most interest in the evolution of feeding modes. Examples include the families Chaetodontidae, Labridae, Pomacanthidae, and Pomacentridae. While these families are considered classic 'coral reef' fish families, they also contain species that are abundant on sub-tropical and temperate rocky reefs as well as other non-reef habitats.

The wrasse family Labridae, including the parrotfish and odacid lineages (Westneat \& Alfaro, 2005), has been the most popular reef fish family for trophic exploration (Westneat, 1995; Westneat et al., 2005; Alfaro et al., 2009; Cowman et al., 2009; Kazancioglu et al., 2009; Price et al., 2011; Lobato et al., 2014). There has been a progressive increase in the phylogenetic resolution of this family and its major lineages over the past decade (Bernardi et al., 2004; Westneat \& Alfaro, 2005; Read, Bellwood \& Van Herwerden, 2006; Cowman et al., 2009; Cowman \& Bellwood, 2011; Choat et al., 2012) although sampling remains incomplete (Cowman, 2014). With over 600 
species (Parenti \& Randall, 2011), labrids and parrotfish represent one of the most diverse reef fish taxonomic groups, second only to the Gobiidae in species richness on coral reefs. Within the family Labridae there is an array of feeding modes (Fig. 1), both specialized and generalist, found globally across coral reef ecosystems. These include gastropod feeders, foraminifera feeders, herbivores, piscivores, planktivores, corallivores and obligate fish cleaners (Wainwright et al., 2004; Bellwood et al., 2006). The rise of the more-specialized feeding modes in Labridae - foraminifera, coral mucous, plankton and ectoparasite feeders (fish cleaners) - dates to the Oligocene/Miocene epoch from 30 to 7.5 million years ago (Ma; Cowman et al., 2009). This second wave in trophic origination comes after an initial establishment of generalist feeding modes (gastropod feeding, piscivory and herbivory) in the Paleocene/Eocene, and appears linked to the expansion of scleractinian-dominated reefs. The evolution of trophic novelty and functional morphological diversity within Labridae occurred more rapidly for those species inhabiting coral reefs (assuming more competition and resource diversity), in comparison to non-reef species (Price et al., 2011). While reef occupation is also linked to higher diversification within families (Cowman \& Bellwood, 2011), species richness and morphological disparity do not seem to be correlated within lineages (Price et al., 2015).

Despite the outstanding diversity of trophic groups found in labrids, certain feeding modes are highly conserved within lineages (Fig. 1). For instance, the variety of modes of herbivory/detritivory (browsing, scraping and excavating) are mostly restricted to the parrotfish clade (Scarini), a lineage that emerged during the early Eocene 48.9 Ma (Cowman et al., 2009). Macroalgae browsing is probably the ancestral mode of herbivory within parrotfish (Cowman et al., 2009), which has been retained in the Atlantic restricted Sparisoma genus, followed by the origin of 'excavating' in Bolbometopon and Chlorurus genera (28.8 and 7.4 Ma), and finally 'scraping' in the Scarus/Hipposcarus lineage (11.8 Ma). The evolution of excavating and subsequently scraping culminated in the critical processes we see today governing reef dynamics: the recycling of reef sediment and reef calcium carbonates, and the grazing of algae (Bonaldo et al., 2014). Over the last 10 million years (Myr) there has been great diversification within the parrotfish group (see Fig. 1), leading to species-rich clades that appear to be associated with a switch to relatively low-quality food ingestion (Lobato et al., 2014). In the Scarus genus alone, there are 53 species (Parenti \& Randall, 2011). Herbivory has also arisen in the hypsigenyines clade: Pseudodax 
moluccanus ( $\sim 30 \mathrm{Ma})$, Odax pullus, O. cyanoallix $(\sim 10 \mathrm{Ma})$ and Neodax balteatus $(\sim 5$ $\mathrm{Ma})$, although most are found on temperate rocky reefs.

Foraminifera feeding, coral feeding and fish cleaning are the most recent feeding strategies in the Labridae family and arose within the crown group julidines (Cowman et al., 2009). Foraminifera feeding evolved approximately 15 Ma being highly conserved across the Macropharyngodon lineage. Coral feeding evolved within the labrichthyines ( $20 \mathrm{Ma}$; Larabicus, Diproctacanthus, Labropsis, Labrichthys genera), as did obligate fish cleaning (less than $10 \mathrm{Ma}$ ), both feeding modes being conserved within lineages. Yet fish cleaning - obligate, facultative and by juveniles - has evolved independently 26-30 times within the Labridae family as a whole (Baliga \& Law, 2016). While cleaning behaviour by juveniles and facultative cleaning appear to be a much more labile trait (Baliga \& Law, 2016), members of the Labroides lineage are the only species in Labridae that are specialized to obligate fish cleaning as adults. In the Labroides lineage, fish cleaning as adults evolved only once and is derived from a coral-feeding lineage in labrichthyines ( $\sim 9$ Ma; Fig. 1). Possibly, the morphological adaptations required to feed on such a specialized diet as ectoparasites were only possible through the already highly adapted coral feeders in the labrichthyines. Within butterflyfishes several species do clean as juveniles (and some even as adults; facultative cleaners), and this habit has also evolved in different clades (Heniochus, Chaetodon and Johnrandallia).

The expansion of reef habitat in the Miocene appears to be important in the functional evolution of many other associated lineages. In the family Chaetodontidae (butterflyfishes and bannerfishes), a switch to coral reef habitat appears to have underpinned elevated cladogenesis of the genus Chaetodon ( 90 species), with subsequent multiple origins (five times) of corallivory within the family (Fig. 2; Bellwood et al., 2010). Obligate corallivory evolved rather recently, over the last 10 Myr (15.7-3.2 Myr, Bellwood et al., 2010), with most species feeding on hard corals and some on soft coral. This feeding mode first appeared in the Chaetodon clade C3, around $\sim 15 \mathrm{Ma}$ (Fig. 2). Within this clade, the majority of taxa are obligate corallivores, exhibiting strong association to the reef substrate (Bellwood et al., 2010). Around $8 \mathrm{Ma}$ this feeding mode evolved in clade 4 (C4 in Fig. 2), although in this lineage species are obligate soft coral feeders and represent significantly fewer lineages. Corallivory can be an extremely specialized diet to the point of species feeding on only a couple of coral species, or ingesting specific parts of the coral, or even feeding only on coral mucous 
216 (Berumen \& Pratchett, 2008; Cole, Pratchett \& Jones, 2008). This move to relatively

217 low-quality food (algae, detritus, sponges and corals) may have accelerated

218 diversification in different reef fish clades (Acanthuroidei, Labridae, Pomacentridae and

219 Chaetodontidae), mediated by ecological opportunity to fill available niche-space

220 (Lobato et al., 2014). Ecological constraints might also lead to diet shifts within

221 lineages, as documented for the Parachaetodon lineage. Departure of Parachaetodon

222 from a coral-based diet to omnivory could be explained by coral decline in a given

223 marine basin (Bellwood et al., 2010). Overall, corallivory evolved very recently and

224 independently across Chaetodontidae, and these shifts may have promoted some

225 diversification within clades, yet significant rate shifts within Chaetodon appeared

226 earlier and are linked with a change to coral reef dwelling (Bellwood et al., 2010,

227 Cowman \& Bellwood, 2011). Today, butterflyfishes are among the most iconic

228 inhabitants of reefs, closely associated with, and indicative of ecological conditions in

229 coral-dominated environments, in the case of obligate corallivore species (Kulbicki,

230 Bozec \& Green, 2005; Pratchett, Berumen \& Kapoor, 2014).

231 Although there is exceptional diversity in corallivorous species found within the

232 chaetodontids, corallivory appeared earlier in the Labridae family, $29 \mathrm{Ma}$ (Fig. 1).

233 According to Bellwood et al. (2010), the shift to corallivory identified in

234 Chaetodontidae coincides with a rise in this feeding mode across other reef fish

235 families. This specialization occured in a context of broader modifications that were

236 taking place in reef environments during the Miocene (from $\sim 23$ to $5 \mathrm{Ma}$ ), including a

237 number of novel reef-fish interactions - foraminifera feeding, fish cleaning, and an

238 increase in detritivory (Harmelin-Vivien, 2002). This revolution in the reef functional

239 system is concordant with the expansion of Acropora and Pocillopora corals (Johnson,

240 Jackson \& Budd, 2008; Bellwood et al., 2016).

241 Damselfishes (family Pomacentridae) have been present in coral reef ecosystems

242 for at least $50 \mathrm{Myr}$ (Bellwood, 1996; Bellwood et al., 2015), being the third most

243 species-rich family on contemporary reefs, after Gobiidae and Labridae (Cooper, Smith

$244 \&$ Westneat, 2009). The pomacentrids comprise over 390 species and might be one of

245 the most successful radiations of coral reef fishes, being diverse, locally abundant

246 (Cooper \& Westneat, 2009; Frédérich et al., 2013), and occupying different trophic

247 niches (Cooper et al., 2009, 2017). Dietary behaviour appears to be the main driver of

248 morphological evolution in damselfishes (Frédérich et al., 2008; Cooper \& Westneat,

249 2009; Aguilar-Medrano et al., 2011; Frédérich \& Vandewalle, 2011). Indeed, similar 
trophic strategies (i.e. pelagic, intermediate and benthic feeding) and morphologies (oral jaw shape and body size) evolved repeatedly across Pomacentridae subclades over the last $20 \mathrm{Myr}$. The diversity of trophic strategies and ecomorphological traits within this family can be attributed to convergent radiations throughout its phylogenetic history, possibly driven by competition, functional constraints and the regionalization of coral reefs (Frédérich et al., 2013). This iterative ecological diversification (predictable patterns in the evolution of phenotypic traits; Losos, 2011) also appears to mediate constant rates of cladogenesis among clades in Pomacentridae (Frédérich et al., 2013). Interestingly, convergence in ecomorphological traits has also been observed in the evolution of triggerfishes (family Balistidae) with distantly related species that are part of the same guild presenting similar skull and jaw muscle structures (McCord \& Westneat, 2016).

The evolutionary history of marine angelfishes (Pomacanthidae) spans at least 38 Myr (Bellwood, van Herwerden \& Konow, 2004; Gaither et al., 2014). Like chaetodontids, pomacanthids represent a conspicuous element of reef assemblages across the globe (Allen, Steene \& Allen, 1998). The family displays a diverse ecology, with striking variations in body size, colour patterns, reproductive systems and diets that range from herbivory to planktivory (Bellwood et al., 2004). Pomacanthids also contain unique functional novelties (Konow \& Bellwood, 2005) that allow the protrusion of the lower jaw, a rare feature in teleost fishes (Westneat \& Wainwright, 1989). Jaw protrusion was key to the evolution of predator-prey interactions of spiny-rayed fishes (acanthomorphs) over the last $100 \mathrm{Myr}$ (Bellwood et al., 2015). During this period, spiny-rayed fishes have become dominant in fish assemblages while the extent of the premaxilla protrusion increased across lineages, enhancing their ability to catch prey (Bellwood et al., 2015). In pomacanthids, further jaw modifications have allowed the closure of the jaw once protruded, creating a 'grab-and-tear' action (Konow \& Bellwood, 2005). This grab-and-tearing feeding mode has appeared only once in the evolutionary history of the family (Konow \& Bellwood, 2011). The combination of variations in gut morphology and disparities in species body size has resulted in the evolution of a range of trophic modes within Pomacanthidae (Konow \& Bellwood, 2011). The large and robust bodies (with strong bites) of Pomacanthus species enabled the utilization of sponges and tunicates as food items. By contrast, small-bodied Centropyge [Xiphypops] feed on delicate foliaceous algae through a combing or shearing strategy (Konow \& Bellwood, 2011). This genus, along with its sister-taxon 
Genicanthus has experienced rapid diversification and represents $25 \%$ of extant angelfish diversity (88 species) (Allen et al., 1998; Konow \& Bellwood, 2011). In their Indo-Pacific angelfish study, Konow \& Bellwood (2011) found that Genicanthus exhibited restricted mouth movements, and its divergent feeding mode within Pomacanthidae corresponds to a functional reversal to planktivory (Howe, 1993; Elliott \& Bellwood, 2003). This dietary shift to an ancestral suction-feeding mode (Lauder, 1982) will be discussed in Section III.

\section{WATER COLUMN USE AND SHIFTS TO PLANKTIVORY}

The level in the water column occupied by a fish species is critical for determining its ecological niche as it influences the set of potential prey items available to consumers as well as patterns of resource use. Evolutionary shifts in water column use can be found across several different reef fish families (e.g. Epinephelidae, Labridae, Kyphosidae, Lutjanidae, Pomacanthidae and Pomacentridae). These shifts require morphological and behavioural adaptations, which may include a slender fusiform body, and a deeply forked caudal fin for swimming and feeding in mid-water on zooplankton (Randall, 1967). These changes usually represent departures from the typical morphology of the family (Randall, 1967). Nevertheless, with recent molecular phylogenies it is now possible to explore shifts in water column use in a comparative framework, combining phylogenies with morphology (e.g. Friedman et al., 2016; Cooper et al., 2017).

It turns out that in many cases, planktivorous species described as separate genera due to different morphologies are in fact nested within other genera (Fig. 3). Examples include the mid-water planktivore Paranthias within the bottom-related Cephalopholis (Craig \& Hastings, 2007); Clepticus within Bodianus (Santini, Sorenson \& Alfaro, 2016); Sectator within Kyphosus (Clements \& Knudsen, 2016); Ocyurus genus placed within Lutjanus (Gold, Voelker \& Renshaw, 2011) and Genicanthus within Centropyge in a secondary functional reversal to planktivory (Bellwood et al., 2004; Konow \& Bellwood, 2011; Gaither et al., 2014). Even the entirely planktivorous Caesionidae family is now placed within Lutjanidae (Miller \& Cribb, 2007). Within Labridae, planktivory appeared in at least three independent lineages - Cirrhilabrus $(\sim 21 \mathrm{Ma})$, Clepticus ( 12.4 Ma), and Pseudocoris ( 7.2 Ma), all during the Miocene epoch (Fig. 1; Cowman et al., 2009), with each origin correlated with a concomitant increase in jaw transmission coefficients (Westneat et al., 2005). For Pomacentridae, Cooper et al. (2017) found that pelagic-feeding damselfishes (planktivores) are strongly differentiated 
from extensively benthic-feeding species (omnivores and herbivores) by their jaw protrusion ability, upper jaw morphology and the functional integration of upper jaw protrusion with lower jaw abduction. The surgeonfishes (family Acanthuridae) also exhibited strong morphological convergence with zooplanktivorous species evolving slender bodies, reduced facial features, smaller teeth and weakened jaw adductor muscles when compared to their grazing relatives (Friedman et al., 2016). Among haemulids, Price et al. (2013) also found that species that feed on zooplankton in the water column present a slender body shape and higher caudal fin aspect ratios.

These diet shifts (transitions to planktivory) may represent cases in which ecological opportunity for the exploitation of different resources drives speciation and adaptation (e.g. Bellwood et al., 2004; Lobato et al., 2014). In damselfishes (Pomacentridae), the story appears more complex with multiple transitions having taken place in several ways (Fig. 4). We observe shifts from bottom to higher water column use exemplified by Amblyglyphidodon shifting to mid-water within Neoglyphidodon, a bottom-dwelling clade. But the reverse is also reconstructed in the Dascyllus lineage, with a shift to a bottom-dwelling habit within the larger Chromis clade, which are generally higher water-column users (although further phylogenetic sampling of Chromis may change this pattern). In general, such shifts have been accompanied by modifications in body shape (see Fig. 3) and a shift to schooling behaviour in the water column. Within the butterflyfishes (Chaetodontidae), transitions have occured from bottom dwelling to the water column exemplified by the Chaetodon sedentariusmiliaris clade, amidst an otherwise bottom-dwelling Exornator subgenus.

In Pomacentridae, transitions have occurred multiple independent times across the family's evolutionary history, maintaining constant cladogenesis rates through time (Frédérich et al., 2013) but with some variation among crown lineages (Cowman \& Bellwood, 2011; Fig. 4). These transitions are also associated with iterative radiations in subclades, and the ability to exploit different sets of resources: zooplankton in the water column; filamentous algae or coral polyps on the substratum; small benthic invertebrates and algae in varying proportions (Cooper \& Westneat, 2009; Frédérich et al., 2009, 2013; Cooper et al., 2017). Diversification over the last $10 \mathrm{Myr}$ of the genus Amphiprion (clownfishes, see Fig. 4), a bottom-dwelling clade, appears to be significantly higher than background diversification rates for the entire family (Cowman \& Bellwood, 2011). This increased diversification rate may have been promoted by the symbioses with sea anemones that characterize this genus (Allen, 1972; Litsios et al., 
2012), although geographic replication of radiations might also play a potential role (Litsios et al., 2014). Similar to Amphiprion, the coral-dwelling genus Gobiodon has diversified in the last $10 \mathrm{Myr}$ in a mutualistic association with Acropora corals (Duchene et al., 2013). While these two cases of mutualistic association are a relatively recent phenomenom, the relationships between fishes and the reef substratum have played out over an extended evolutionary history.

The late Cretaceous marks the rise of stem lineages of many modern reef fish families (Near et al., 2013; Bellwood et al., 2015). It is also during this period that morphological changes accompanying the diversification of acanthomorph fishes would have paved the way for the future fish assemblages found on coral reefs. The Paleocene and Eocene epochs (66-34 Ma) represent a phase in the evolutionary history of reef systems where the crown fossil precursors of modern acanthomorph fish families had both the geographic proximity and the morphological proclivity to form the foundation of the modern coral reef fish assemblage (Bellwood et al., 2015). The origins and crown diversification of many functional guilds (e.g. herbivory in surgeonfishes and rabbitfishes, scraping and excavating in wrasses) are most likely associated with the rise of scleractinian-dominated coral reefs (Wallace \& Rosen, 2006), allowing rapid expansion into new niche space (Bellwood, 2003; Goatley et al., 2010; Wainwright et al., 2012; Bellwood et al., 2015). But the reverse may also be true. There is evidence to suggest that the movement of fishes into shallow water areas and the expansion of herbivory paved the way for corals to invade what we now see as the highly productive reef flat of a modern coral reef system (Wood, 1999; Bellwood et al., 2016). Modern groups such as scraping parrotfishes and corallivorous butterflyfishes appeared in the Neogene (23-3 Ma), which coincided with diversification in several coral groups (e.g. Acropora) from $\sim 20 \mathrm{Ma}$ onwards. The evolutionary history of reef fishes over the last 5 Myr has been mainly decorative - 'baubles on the tree of life', as coined by Bellwood et al. (2015) - characterized by new combinations of colours and shapes in fish species. Despite the appearance of new colours and shapes that accounted for some diversification during this time, there appears to be no further functional differentiation in reef fishes or new functional modes occupied (e.g. Labridae; Cowman et al., 2009).

\section{THE EVOLUTION OF BODY SIZE IN REEF FISHES}

Body size is one of the most important traits in ecological studies, being related to other parameters such as geographical distribution (Blackburn, Gaston \& Loder, 1999; Luiz et 
al., 2013), temperature, metabolism (Brown et al., 2004; Barneche et al., 2014), abundance (White et al., 2007), and even vulnerability to extinction (Reynolds et al., 2005; Cheung, Pitcher \& Pauly, 2005; Olden, Hogan \& Zanden, 2007; Bender et al., 2013a). Additionally, body size is commonly used as a proxy for many life-history traits, such as longevity, reproductive output, range size (Reynolds, Jennings \& Dulvy, 2001) and other ecological features, such as type and size of prey that can be consumed and predator-avoidance abilities (Peters, 1986; LaBarbera, 1989; Harmon et al., 2010). Across the ray-finned fish there appears to be an overarching link between the rate of body-size evolution and the rate of lineage diversification (Rabosky et al., 2013). Historically, it seems that smaller-bodied reef fish species were least able to colonize distant habitats after past climatic fluctuations during the Quaternary (Ottimofiore et al., 2017), reinforcing this trait as an important determinant of biodiversity patterns in reef environments. While body size in reef fishes has been extensively studied from an ecological perspective (reviewed by Kulbicki, Parravicini \& Mouillot, 2015) it has yet to be explored for its evolutionary and phylogenetic significance.

Here we mapped body size distributions onto the Labridae family phylogeny (Fig. 5). Most labrids are of medium size (10-40 cm; seen in green shades in Fig. 5). Larger sizes were mainly observed in the tribes Hypsigenyini, Cheilini and Scarini, while the smaller body sizes appeared in Pseudocheilinus and in some clades within the julidine crown group. The humphead wrasse (Cheilinus undulatus) stands out as the largest labrid, reaching up to $230 \mathrm{~cm}$, while Hemigymnus melapterus reaches the largest sizes $(\sim 60 \mathrm{~cm})$ within the crown julidine clade. There seems to be no relationship between body size and lineage age within labrids, and both large and small body sizes appear multiple times within the clades of mid-sized fishes. Nevertheless, the majority of extreme body sizes - largest (red in Fig. 5) and smallest (dark blue) - emerge in lineages that have arisen in the last $10 \mathrm{Myr}$ across the Labridae phylogeny, even though there are few older, small-sized clades that date back to the mid-Miocene.

In Pomacentridae, the evolution of body size throughout the phylogeny is related to the appearance of different trophic strategies, with benthic feeders exhibiting smaller optimal sizes when compared with pelagic and intermediate feeders (Frédérich et al., 2013). These trophic strategies and consequently body size within damselfishes have undergone multiple convergent radiations possibly shaped by common ecological selection pressures (Frédérich et al., 2013). Although presenting little structural and functional disparity, angelfishes (Pomacanthidae) evolved a wide range of body sizes, 
which also appears to be strongly related to the trophic evolution of the family (Konow $\&$ Bellwood, 2011). The opposite trend was observed for the Tetraodontidae (pufferfishes) with reef-associated lineages presenting lower body size disparity when compared to freshwater species, even though reef environments might have promoted rapid diversification of two pufferfish genera (Arothron and Canthigaster; Santini et al., $2013 a$ ). Within Chaetodontidae there is low variation in body size, with $80 \%$ of all species being within 10 to $20 \mathrm{~cm}$, which might be related to their dependency and specialization for living in complex three-dimensional coral reef habitats.

\section{HABITAT USE, RANGE SIZES AND BIOGEOGRAPHY OF REEF FISHES}

\section{(1) Habitat use}

Habitat-use patterns have had a key role in the evolution of reef fishes. A number of studies have documented ecological radiations of fish clades following the colonization of reef habitats, where the reef complexity provided unique and novel ecological opportunities (Alfaro, Santini \& Brock, 2007; Cowman \& Bellwood, 2011; Price et al., 2011; Santini et al., 2013a). The expansion of a complex mosaic of reef habitats during the Miocene has driven elevated cladogenesis across several reef fish clades in Acanthuridae (Lobato et al., 2014), Labridae, Pomacentridae, Chaetodontidae and Apogonidae (Cowman \& Bellwood, 2011), Tetraodontiformes (Alfaro et al., 2007; Santini et al., 2013a), and Carcharhinidae (Sorenson, Santini \& Alfaro, 2014).

Bellwood et al. (2016) proposed that an increase in the range of habitats occupied, such as reef flats, was related to novel morphologies for increasing swimming ability to cope with hydrodynamic challenges (e.g. high-aspect-ratio pectoral fins in labrids, shift in eye position and caudal peduncule depth in surgeonfishes). The expansion of scleractinian-dominated reef habitats throughout the Miocene can also be associated with the rise of one the most specialized swimming modes within the balistoid fishes (triggerfishes and filefishes) using coupled oscillation or ondulation of paired median fins (Dornburg et al., 2011; Santini, Sorenson \& Alfaro, 2013b). Reef association also seems to offer some resistance to extinction where lineages with higher reef occupation remain significantly more diverse than expected when faced with high (simulated) rates of extinction (Cowman \& Bellwood, 2011).

In Haemulidae, habitat use has also influenced the diversification of lineages and extant patterns of diversity. While hard bottom environments are inhabited by few but very speciose haemulid lineages (e.g. Plectorhinchus, Haemulon, Anisotremus), in soft 
454 bottoms there are a greater number of genera, yet with fewer species (Tavera et al.,

455 2012). Haemulids exhibit similar patterns of species richness and ecological diversity

456 both on and off reef habitats. However, those haemulid lineages that are reef associated

457 display increased rates of ecomorphological evolution compared with their counterparts,

458 especially in trophic traits related to prey capture and processing (see Price et al., 2013).

459 A similar pattern is also seen in labrids where tropical reef-associated lineages exhibit

460 faster rates of evolution in trophic ecomorphological space compared to tropical non-

461 reef lineages (Price et al., 2011).

462 Although there seems to be a congruent pattern of higher ecomorphological

463 diversification associated with groups that present specialized diets such as planktivory,

464 herbivory or invertivory, piscivorous groups may follow different evolutionary paths.

465 By analysing carangoid fishes (jacks, remoras and allies), which include some

466 piscivorous reef-associated species, Frédérich et al. (2016) found that a higher rate of

467 morphological diversification is associated with habitat shifts to non-reef environments.

468 These results do not exclude the important role of reef habitats in the early

469 diversification of carangoids during the Eocene, however, it highlights that the major

470 radiation of the group occurred recently in non-reef environments (Frédérich et al.,

471 2016). Similarly, the diversification of grouper lineages (family Epinephelidae) does not

472 seem to be correlated with the expansion of coral habitats in the Miocene and might

473 have been more influenced by global environmental changes during this period (Ma et

$474 a l ., 2016)$. In contrast to these results, Sorenson et al. (2014) found that reef association

475 is significantly correlated with requiem shark diversification, showing that the drivers of

476 diversification for piscivorous reef species are idiosyncratic and deserve greater

477 attention. Multiple transitions between reef and non-reef habitats have also been

478 reported for the piscivorous barracudas (family Sphyraenidae) (Santini, Carnevale \&

479 Sorenson, 2015), however, it remains unclear whether these shifts represent significant

480 departures from the background rate of diversification for the group.

481 Understanding how shifts in habitat use have influenced the rates of morphological and lineage diversification are critical for understanding the functional history of reef systems. In the case of reef occupation, this requires accurate knowledge of the intial transition into shallow-water reef habitat. Using labrids as an example, there is a possible basal shift to reef habitat in the labrid tree when comparing the relatively non-reef-associated hypsigenyine lineage to non-hypsigenyines, which are more reef associated (Cowman et al., 2009). However, given the lack of knowledge of the true 
sister group to the Labridae (Cowman, 2014), the exact timing of ancestral reef occupation of labrid lineages cannot be known for certain. Yet, there are several labrid fossils in Eocene deposits (50 Ma) that suggest at least proximity to shallow water reef systems (Bellwood, 1996).

A broader taxonomic and temporal view of the occupation of ancestral shallowwater reef systems across all Acanthomorpha (spiny-rayed fishes) outlines the deep evolutionary history of reef association and how multiple families have independently transitioned into reef habitat (Price et al., 2014). The study of Price et al. (2014) highlights that the colonization of ancestral reef systems by acanthomorph lineages potentially occurred in two waves of invasion either side of the Cretaceous-Paleogene $(\mathrm{K}-\mathrm{Pg}$ ) boundary ( $\sim 66 \mathrm{Ma})$. The first wave of invasion possibly took place in the Late Cretaceous (90-72 Ma), and the second occurred during the early Paleogene, following the $\mathrm{K}-\mathrm{Pg}$ mass extinction (65-56 Ma). These waves of reef invasion might have been related to changes in reef structure and climate (Price et al., 2014). While colonizing new habitats such as the reef environment, fish lineages underwent morphological convergence. Such a process fits the macroevolutionary niche-filling scenario of Ricklefs (2010), where the ecological opportunities found in new habitats promote functional convergence of species and clades, followed by saturation of the morphospace. As the functional space in reef-associated lineages became increasingly saturated, there was a slowdown in the pace of reef invasions by acanthomorphs.

\section{(2) Range size and biogeography}

Geographical range can be viewed as a property that results from the combination of different species traits (e.g. body size, reproductive mode, trophic group, dispersal potential) subjected to environmental constraints through time. In addition, range size, or space occupancy, is generally associated with commonness or rarity and thus may be related to the vulnerability of species (Connolly et al., 2014; Parravicini et al., 2014; but see Hughes et al., 2014). Despite its relevance, only a handful of studies have explored range size in the context of within-genus evolutionary relationships (Hodge et al., 2012) or species age (Mora et al., 2012). Here we performed a reconstruction of range size, given by the number of grid cells occupied by each species (each $5^{\circ} \times 5^{\circ}$ grid cell corresponds to approximately $550 \times 550 \mathrm{~km}$ at the equator) across the marine tropics, on a time-calibrated phylogenetic tree for Labridae (Fig. 6). This reconstruction shows that for labrids, range size appears constrained by the geography and size of ocean 
basins (reviewed by Ruttenberg \& Lester, 2015). For example, fishes from Atlantic or Tropical East Pacific (TEP) clades (e.g. members of the genus Scarus such as $S$. guacamaia and the 'Iridio' clade among Halichoeres such as H. socialis; see Fig. 6) tend to have much smaller geographical ranges compared to congeners occurring in the Indo-Pacific. There also appears to be a temperate versus tropical range effect. Clades restricted to temperate areas such as the genera Labrus, Symphodus, Notolabrus, Pseudolabrus, and Odax also tend to have small ranges when compared to more tropical clades. Similarly, chaetodontid species with Atlantic and TEP distributions as well as the warm temperate genus Amphichaetodon have smaller ranges. These patterns may be related to overall differences in the size of ocean basins, and historical availability and stability of habitats (Ottimofiore et al., 2017), as well as different extinction rates among basins (e.g. O'Dea et al., 2007) and latitudes (Siqueira et al., 2016). Estimates of phylogenetic dissimilarity of reef fish assemblages also highlight variations in reef connectivity and provinciality through time (Cowman et al., 2017).

Reef fishes vary dramatically in the extent of their geographic distributions (Ruttenberg \& Lester, 2015), however, few within-clade analyses of range size are available to date (but see Hodge et al., 2012; Hodge \& Bellwood, 2016). The reconstruction of range size in labrids (Fig. 6) highlights many cases of disparate range sizes among sister-species pairs, complexes and clades such as Thalassoma purpureumvirens, Coris aygula-flavovittata, the Scarus 'rubroviolaceus' clade (Fig. 7), Macropharyngodon meleagris-geoffroy (Read et al., 2006), and Anampses (Hodge et al., 2012). Three models of diversification could explain these intriguing cases: the vicariance-based 'successive division' model, the dispersal-based 'successive colonization' model and the 'peripheral budding' model (sensu Hodge et al. 2012).

Although species range sizes are restricted by the size of ocean basins in which they occur, it is possible to expect that older lineages have had more time to disperse, reaching greater geographic range sizes compared to recently diverged species (but see Mora et al., 2012). In addition, a species' body size has been shown to be related to its range size, with large-bodied species exhibiting greater ranges compared to smaller ones (Gaston \& Blackburn, 1996; Luiz et al., 2013). The relationship between the age of 303 Labridae species and their range size, measured as the number of grid cells occupied by each species, revealed no significant pattern of species range size distributions with lineage age (Fig. 8A, B). This is not surprising given the effects that peripheral speciation and range persistence can have on age-area relationships (Hodge \& 
Bellwood, 2015). When a sister-pair approach is taken, in an effort to mitigate peripheral speciation processes (Hodge \& Bellwood, 2016), a significant, albeit weak trend emerges between labrid range size and lineage age (Fig. 8C, D; $r^{2}=0.03 ; N=191$; d.f.=1,189; $F=5.94 ; P=0.015$ ), where the minimum range size of sister-species pairs increases linearly with lineage age. When 'basin' (Indo-Pacific + TEP vs. Atlantic) was included as an effect in the regression model, there was also a significant relationship between minimum range size and age, but much more of the variation is explained by the model $\left(r^{2}=0.18 ; N=191 ;\right.$ d.f. $\left.=2,188 ; F=21.3 ; P<0.001\right)$. This significant result remains when the data are $\log -\log$ transformed to account for positive skeweness $\left(r^{2}=0.18 ; N=191 ;\right.$ d.f. $\left.=2,188 ; F=20.9 ; P<0.001\right)$. This basin effect likely reflects the difference in range-size dynamics and biogeographic history of the two regions. Range sizes are far more evenly distributed across a broader size range in the Indo-Pacific compared to the Atlantic (Fig. 8). There was no clear impact of maximum body size (circle size in Fig. 8), or diet on the relationship between minimum range size and age. At least for labrids, species with different body sizes and trophic modes occupy a large spectrum of range sizes across both basins, regardless of age. A similar pattern for trophic mode and range size was found by Luiz et al. (2013). A more in-depth temporal view of functional evolution across multiple traits of reef fish assemblages is needed to understand how trait variation is partitioned across geographic and geological scales.

\section{FUNCTIONAL EVOLUTION OF REEF FISH ASSEMBLAGES}

\section{(1) Multi-trait comparisons, lineage accumulation and disparity through time}

Multi-trait comparisons, from a phylogenetic perspective, presents an opportunity to examine how complex ecological patterns have played out over evolutionary timescales. Examining the relationship between cladogenesis (diversification) and the evolution of phenotypic variation (disparity) can tell us a great deal about how a clade has radiated and the role life-history traits have played in its diversification. In Fig. 9, we synthesize some emerging patterns for the families Labridae, Pomacentridae and Chaetodontidae over the last $60 \mathrm{Myr}$, based on phylogenetic and trait reconstruction, and estimates of disparity through time.

Lineage through time (LTT) plots display the tempo of diversification through time (Fig. 9A). Cowman \& Bellwood (2011) proposed that an antisigmodal pattern in Labridae (and potentially in Pomacentridae) may point to a cryptic extinction event ( $c f$. Crisp \& Cook, 2009) linked to the collapse of ancestral biodiversity hotspots (Renema 
et al., 2008). Comparatively, the evolution of butterflyfishes has played out over a shorter timescale. With a crown divergence of $\sim 33$ Ma the chaetodontids perhaps show less sign of the collapse of ancestral habitat to the west and are tied to the expansion of shallow-water reef systems in the central Indo-Pacific. They display a birth/death pattern of lineage accumulation with a possible rate shift at the base of the crown Chaetodon lineage (Cowman \& Bellwood, 2011). Nevertheless, the functional evolution of this group reflects a pattern similar to that of labrids where more trophic innovation within lineages occurs in the Miocene.

The stacked density plot of ancestral trait reconstructions reflecting trophic evolution and water column use (Fig. 9B) shows the proportion of nodes that were reconstructed with the highest likelihood for each trait examined. In the Labridae, the expansion of herbivory/detritivory and specialized feeding modes begins in the Oligocene and continues into the Miocene, a time that sees massive expansion of coral reefs in the Indo-Pacific. A jump in the number of nodes reconstructed with herbivory and detritivory coincides with the origins of the Scarus and Chlorurus lineages, which also represents a shift in the rate of lineage diversification (Cowman \& Bellwood, 2011) and significant morphological divergence (Price et al., 2011). However, there is only weak support for a relationship between the two (Alfaro et al., 2010). These results mirror those of Cowman et al. (2009) which show expansion of novel feeding modes during the Oligocene and Miocene and point to a closer association between wrasses and the reef substratum during this time. Similarly, the origins of corallivory in the butterflyfishes show a signal of expansion in the mid-Miocene coinciding with the evolution of that feeding mode in several independent lineages (Bellwood et al., 2010). Water column use in the Pomacentridae appears to show no consistent pattern in magnitude of transistions through time from bottom dwelling to higher water column users. From the phylogenetic reconstruction (Fig. 4), it is clear that shifts to higher water column use occurred in subclades throughout the phylogeny with only one instance involving a transition back to bottom dwelling in the Dascyllus lineage.

A positive disparity index through time (DTT) for body size for all three families indicates that the subclade disparity in body size is higher then expected under a Brownian motion model (Fig. 9C). This, along with no evidence of a slowdown in rates of cladogenesis in these groups (Cowman \& Bellwood, 2011), shows that in these reef fish families there is little evidence of a single process of adaptive radiation. These disparity methods have been used previously to explore adaptive radiations in cetaceans 
624 (Slater et al., 2010), the rodent genus Rattus (Rowe et al., 2011), and lizards (Harmon et

al., 2003). Patterns here suggest that body size variation in reef fishes is partitioned within clades more than among clades (although not significantly so). Such a pattern was also found by Frédérich et al. (2013) for Pomacentridae body size and jaw morphology. They concluded that such disparity patterns highlight iterative ecological diversification rather than single adaptive radiation. Similarly here, body size patterns in Labridae and Chaetodontidae show far higher disparity within clades than among them, with the pattern most apparent in the Chaetodontidae. Butterflyfishes, however, display little body size variation, so any small changes in body towards the tips will result in higher estimates of disparity. It is interesting to note that Dornburg et al. (2011) found a low body shape disparity through time for triggerfishes (family Balistidae), suggesting a pulse of phenotypic and functional innovation early in the history of the group with a subsequent slowdown in shape disparity. They also found that this early morphological disparity was decoupled from lineage diversification in triggerfishes (Dornburg et al., 2011), which reinforces a common pattern in reef fish evolutionary history (Price et al., 2015).

Although non-morphological traits are not commonly examined in this manner, assessments of disparity through time have been useful for examining extinction threat and range size in angiosperms (Davies et al., 2011). For the reef fish families examined, as with body size, range size disparity through time shows more disparity within clades than among them and more so toward the tips of the trees (Fig. 9D). This pattern highlights two things: first, more closely related species show larger asymmetries in range size towards the tips. An implication of this pattern could be an observed higher asymmetry in extinction risk as was previously observed in angiosperms (Davies et al., 2011). Second, this points towards the influence of peripatric and peripheral isolation mechanisms in speciation of these groups. This supports the relationship between lineage age and geographic range size discussed above (Fig. 8), where a significant relationship is only found in minimum geographic range size of sister pairs ( $c f$. Hodge $\&$ Bellwood, 2016). Higher asymmetries outside the $95 \%$ range in all three families is seen from $20 \mathrm{Ma}$ onward, a pattern concordant with body size disparity, and trophic expansion within the Labridae and Chaetodontidae. Although there are several clades in all three families that have deep-time separation among ocean basins, there is consistently higher disparity in range size within clades than among them. 
Functional trait approaches may enlighten the understanding of community assembly patterns and processes (McGill et al., 2006). At the local scale, the analysis of patterns of traits among co-occurring species offers insights into the influence of the link between short-term local processes and those that occur at global and evolutionary timescales (Fig. 10). Moreover, trait-based studies provide the basis to assessments of functional diversity, redundancy or insurance, as well as the provision of services (Mouillot et al., 2013, 2014). Nevertheless, such approaches are conducted at local spatial and time scales, often without an evolutionary perspective. Thus, they can offer only a snapshot of communities, without insight into the totality of mechanisms that have shaped extant reef fish communities. When trait-based approaches are coupled with phylogenetic analyses of local communities, it is possible to assess which species traits have strongly influenced the evolutionary history of regional assemblages and local communities, as well as to uncover the mechanisms of species assembly (Fig. 10; Cavender-Bares et al., 2009; Gerhold et al., 2015).

The main focus of most studies of reef fish communities has been the evolution of traits across lineages (Cowman et al., 2009; Bellwood et al., 2010; Price et al., 2013; Lobato et al., 2014), where the evolutionary patterns of specific traits are mapped into a reconstructed phylogeny (in Fig. 10 shown by the phylogeny on the left representing the regional pool of species and its traits). On the other hand, trait-based approaches to the study of local communities combined with phylogenies have been developed under the research area of phylogenetic community ecology (see Webb et al., 2002; CavenderBares et al., 2009). Such approaches can reveal the processes that have shaped different communities through time (in Fig. 10 shown by the phylogenies on the right depicting the phylogenetic structure of local communities). The transition from regional to local scales occurs across spatial and temporal scales, through the effect of biotic (e.g. species interactions, dispersal limitation, habitat specificity, local population structures) and abiotic filters (e.g. distance from a source pool, temperature, area, habitat availability, etc.). These filters determine the structure of local communities, both phylogenetically and functionally. At the local scale, communities may exhibit the following structures (shown in Fig. 10): phylogenetic and functional clustering (C1); phylogenetic clustering and functional overdispersion (C2); phylogenetic and functional overdispersion (C3); and phylogenetic overdispersion and functional clustering (C4). 
Investigating the phylogenetic and functional structure of communities enables the identification of the ecological factors that have played a role in structuring communities through evolutionary time. For instance, in Fig. 10, community $\mathrm{C} 1$ has been shaped by environmental or biotic filters acting on phylogenetically conserved traits - under the hypothesis of niche conservatism where species with shared ancestry present similar phenotypes (Webb, 2000; Wiens \& Graham, 2005; Losos, 2008). Such fish species composition and trait assembly (in $\mathrm{C} 1$ ) could have been structured by the effect of isolation, for instance, filtering related species with a particular trait that facilitates dispersal, colonization and persistence (e.g. body size, rafting capacity; Luiz et al., 2013). Moreover, this structure could result from the selective forces of generalist predators acting on conserved defence traits (Cavender-Bares et al., 2009). Hypothetically, predators could filter closely related species that share a particular swimming or escape ability to persist in local communities.

Environmental and biotic filters can also cause phylogenetic overdispersion if selected traits are labile and related species occupy different niches, where ecological divergence is driven by competition (Schluter, 2000; C3 and C4 in Fig. 10). If traits were convergent across lineages, then habitat or biotic filtering would result in functional clustering of communities (seen in $\mathrm{C} 4$ ). For instance, the increased richness patterns of small-bodied fishes in the centre of marine biodiversity may possibly reflect the degree of feeding and microhabitat specialization of species belonging to different lineages (e.g. Gobiodon, Halichoeres). Furthermore, the effects of past environmental change (over species pools) have certainly shaped contemporary patterns of the phylogenetic and functional structure of communities. In coral reefs, Quaternary climate fluctuations have influenced the geological complexity and availability of coral reef habitats for associated fish fauna with areas of stable refugia being a strong predictor of current richness patterns of reef fishes at a global scale (Pellissier et al., 2014). Such historical processes have shaped the global patterns of phylogenetic and functional structure in reef fish lineages (Ottimofiore et al., 2017). The families Pomacentridae, Chaetodontidae and Labridae exhibited high phylogenetic clustering in the IndoAustralian Archipelago, partly due to vicariance events resulting from reef fragmentation (Leprieur et al., 2016). These tracked responses of assemblages to past environmental and biotic effects may help us understand the capacity of current communities to respond to global changes such as fishing pressure, climate change, habitat loss and species extinctions. 


\section{FUTURE DIRECTIONS}

727 The study of coral reef fish traits has included both ecological and phylogenetic approaches. Ecological assessments have covered the functional structure of reef fish communities along gradients of diversity, coral reef area, isolation, sea surface temperature, etc., from local (Guillemot et al., 2011; Micheli et al., 2014) to regional (Halpern \& Floeter, 2008; Bender et al., 2013b) and up to global scales (Stuart-Smith et al., 2013; Mouillot et al., 2014; Parravicini et al., 2014). These studies have addressed aspects of functional diversity that are important to reef conservation, encompassing functional insurance, redundancy, and ecosystem services (Micheli et al., 2014; Mouillot et al., 2014; Parravicini et al., 2014). In parallel, phylogenetic studies have examined the evolutionary patterns of a variety of traits in reef fish lineages, aligning their findings to key historical and biogeographical events and evolutionary processes that have shaped reef fish functional diversity (Alfaro et al., 2009; Erisman, Craig \& Hastings, 2009; Bellwood et al., 2010; Price et al., 2011; Frédérich et al., 2013; Lobato et al., 2014). Community phylogenetics combines ecology with phylogeny to offer a framework to examine the functional history of an assemblage, but also to address how assemblage structure and function are shaped by evolutionary processes. to assess coral reef fish communities (e.g. Hubert et al., 2011; Leprieur et al., 2016), and the functional aspect is yet to be integrated. Functional entities, or groups of species with distinct functional trait combinations, have been described in reef fish communities and related to ecosystem processes, functional redundancy, and vulnerability to extinction (Mouillot et al., 2014). The lack of a phylogenetic component in these studies means that while we can identify which species and which functional roles are redundant or vulnerable, we do not know the origin of these functional entities or the evolutionary histories of the trait combination they represent. Future multi-trait phylogenetic assessments will highlight how trait combinations are shared among closely related species and how they are functionally and phylogenetically structured in local and regional assemblage pools allowing for more integrated conservation solutions. Such an endeavour is becoming more achievable with the rapid improvement of molecular data generation for reef fishes and improvements in phylogenetic sampling and resolution. This resolution, combined with knowledge on species traits and distributional patterns across the globe, will make these studies feasible at global scales. 
In sum, combining phylogenetic and trait-based approaches to the better understanding of ecosystem functioning is an emerging topic and key to the promise of so-called Functional Biogeography (Violle et al., 2014).

The presence of specific traits, or trait combinations can influence a species' capacity to respond and adapt to climatic stress, ultimately influencing patterns of dispersal, colonization, speciation and extinction (Puebla et al., 2007; Luiz et al., 2013; Bender et al., 2013a; Ottimofiore et al., 2017). Links between several functional traits and accelerated cladogenesis in the most phylogenetically well-sampled reef fish families have been described here, although further sampling of clades with reef and non-reef components still need to be examined to assess the generality of these trends. It is unclear how or if functional 'success' at the macroevolutionary level (high species diversity within functional roles) scales down to the individual level (species abundance). The next frontier in community phylogenetics requires the inclusion of patterns of abundance of co-occurring taxa to examine population-level effects of species-level interactions. While species traits influence the distribution of organisms and the structure of communities, interactions among co-occurring species will influence the presence of traits within communities and evolutionary processes driving speciation and adaptation (Bascompte \& Jordano, 2007; Jablonski, 2008; CavenderBares et al., 2009). These future studies will help identify the role of abundance at ecological and evolutionary timescales.

\section{CONCLUSIONS}

(1) Species functional traits form a link between evolutionary history and the ecological proceses shaping lineages. By mapping functional traits onto species-level phylogenies, we can examine their evolutionary origins and their influence on lineage diversification. This functional view to evolutionary history is important in the study of present-day biodiversity patterns. In the case of modern reef systems, fish functional traits related to food aquistion and locomotion have been important for driving speciation but also in shaping ecosystem processes.

(2) Ancestral trait reconstruction for feeding modes in labrids showed an early establishment of herbivory and subsequent origins of detrivory in parrotfishes, a critical reef process. Trophic evolution can be conserved within clades as in labrids, or reflect multiple independent origns such as corallivory in butterflyfishes. From reconstructions across several groups we show examples of independent transitions to planktivory that 
may represent cases in which ecological opportunity for the exploitation of different resources drives speciation and adaptation.

(3) Body size is often used as a proxy for other life-history characteristics, but its evolutionary history is not well studied at the species level. The evolution of body size in the family Labridae shows no relationship with lineage age, with both large and small body sizes appearing multiple times within clades of mid-sized fishes. Extremely large and small body sizes arise in disparate lineages mostly in the last $10 \mathrm{Myr}$. Labridae and Chaetodontidae show higher body size disparity within clades than among them through time. In the Pomacentridae, body size evolution appears closely linked with the convergent evolution of different trophic strategies among clades.

(4) The reconstruction of range size in Labridae revealed that ranges are mostly constrained by the geography and size of ocean basins. When accounting for peripheral speciation processes in sister pairs, we found a significant relationship between labrid range size and lineage age. The reconstruction of disparate ranges among sister-species pairs and species complexes and range size disparity through time highlights potential vicariant processes through isolation in peripheral locations with subsequent range expansion.

(5) Ecological approaches to the study of life-history traits in reef-associated fishes have unveiled the functional structure of communities across biodiversity and environmental gradients. Evolutionary approaches mapping the phylogenetic origins of species groups within reef communities correlate to historical processes acting on the distribution of reef habitat through time. With the increasing availability of phylogenies (with complete or nearly complete taxon sampling) a combined phylogenetic and functional approach will allow a number of evolutionary and ecological questions to be addressed in the near future that will certainly help us to uncover the mechanisms of community assembly over space and time.

\section{ACKNOWLEDGMENTS}

We thank M. Kulbicki for his insightful comments and L.A. Rocha and C.E.L. Ferreira for sharing their expertise on reef fishes. This work took advantage of databases compiled for the GASPAR Program (M. Kulbicki, P.I.). The GASPAR program is part of the CESAB initiative financed by the Foundation pour la Recherche en Biodiversité (FRB). S.R.F. and M.G.B. were funded by Conselho Nacional de Desenvolvimento Científico e Tecnológico (CNPq) - Brazil (305358/2015-4 and 503384/2014-3). P.F.C. was funded by the Gaylord Donnelley Postdoctoral Environment Fellowship 
administered by the Yale Institute for Biospheric Studies (YIBS) and the ARC Centre of Excellence for Coral Reef Studies.

\section{REFERENCES}

ACKERLY, D. (2009). Conservatism and diversification of plant functional traits: evolutionary rates versus phylogenetic signal. Proceedings of the National Academy of Sciences of the United States of America 106, 19699-19706.

Aguilar-Medrano, R., Frédérich, B., De Luna, B. \& Balart E. F. (2011). Patterns of morphological evolution of the cephalic region in damselfishes (Perciformes: Pomacentridae) of the eastern Pacific. Biological Journal of the Linnean Society 102, 593-613.

Alfaro, M. E., Brock, C. D., Banbury, B. L. \& Wainwright, P. C. (2009). Does evolutionary innovation in pharyngeal jaws lead to rapid lineage diversification in labrid fishes? BMC Evolutionary Biology 9, 255.

Alfaro, M. E., SAntini, F. \& Brock, C. D. (2007). Do reefs drive diversification in marine teleosts? evidence from the pufferfish and their allies (order Tetraodontiformes). Evolution 61, 2104-2126.

Allen, G. R. (1972). The Anemonefishes: Their classification and biology. Tropical Fish Hobbyist Publications, Neptune City.

Allen, G. R., Steene, R. \& Allen, M. (1998). A Guide to Angelfishes and Butterflyfishes. Odyssey Publishing, Perth.

BALIGA, V. B. \& LAw, C. J. (2016). Cleaners among wrasses : phylogenetics and evolutionary patterns of cleaning behavior within Labridae. Molecular Phylogenetics and Evolution 94, 424-435.

Barneche, D. R., Kulbicki, M., Floeter, S. R., Friedlander, A., Maina, J. \& Allen, A. (2014). Scaling metabolism from individuals to reef-fish communities at broad spatial scales. Ecology Letters 17, 1067-1076.

BASCOMPTE, J. \& JORDANO, P. (2007). Plant-animal mutualistic networks: the architecture of biodiversity. Annual Review of Ecology, Evolution, and Systematics 38, 567-593.

Bellwood, D. R. (1996). The Eocene fishes of Monte Bolca: The earliest coral reef fish assemblage. Coral Reefs 15, 11-19.

BELLWOOD, D. R. (2003). Origins and escalation of herbivory in fishes: a functional perspective. Paleobiology 29, 71-83.

Bellwood, D. R., Goatley, C. H. R. \& Bellwood, O. (2016). The evolution of fishes and corals on reefs: form, function and interdependence. Biological Reviews (doi: 10.1111/brv.12259).

Bellwood, D. R., Goatley, C. H. R., Brandl, S. J. \& Bellwood, O. (2014a). Fifty million years of herbivory on coral reefs: fossils, fish and functional innovations. Proceedings of the Royal Society of London Series B: Biological Sciences 281, 20133046.

Bellwood, D. R., Goatley, C. H. R., Cowman, P. F., Bellwood, O. \& Mora, C. (2015). The evolution of fishes on coral reefs: fossils, phylogenies and functions. 
Ecology of Fishes on Coral Reefs (ed. C. Mora), pp. 55-63. Cambridge University Press, Cambridge.

Bellwood, D. R., Hoey, A. S., Bellwood, O. \& Goatley, C. H. R. (2014b). Evolution of long-toothed fishes and the changing nature of fish-benthos interactions on coral reefs. Nature Communications 5, 3144.

Bellwood, D. R., Klanten, S., Cowman, P. F., Pratchett, M. S., Konow, N. \& van HERWERDEN, L. (2010). Evolutionary history of the butterflyfishes (f: Chaetodontidae) and the rise of coral feeding fishes. Journal of Evolutionary Biology 23, 335-49.

Bellwood, D. R., van Herwerden, L. \& KonOw, N. (2004). Evolution and biogeography of marine angelfishes (Pisces: Pomacanthidae). Molecular Phylogenetics and Evolution 33, 140-155.

Bellwood, D. R., Wainwright, P. C., Fulton, C. J. \& Hoey, A. S. (2006). Functional versatility supports coral reef biodiversity. Proceedings of the Royal Society of London Series B: Biological Sciences 273, 101-107.

Bender, M. G., Floeter, S. R., Mayer, F., Vila-Nova, D. A., Longo, G. O., Hanazaki, N., CARvalho-Filho, A. \& Ferreira, C. E. L. (2013a). Biological attributes and major threats as predictors of the vulnerability of species: a case study with Brazilian reef fishes. Oryx - The International Journal of Conservation 47, 259-265.

Bender, M. G., Pie, M. R., Rezende, E. L., Mouillot, D. \& Floeter, S. R. (2013b). Biogeographic, historical and environmental influences on the taxonomic and functional structure of Atlantic reef fish assemblages. Global Ecology and Biogeography 22, 1173-1182.

Bernardi, G., Bucciarelli, G., Costagliola, D., Robertson, D. R. \& Heiser, J. B. (2004). Evolution of coral reef fish Thalassoma spp. (Labridae). 1. Molecular phylogeny and biogeography. Marine Biology 144, 369-375.

BERUMEN, M. L. \& PRATCHETT, M. S. (2008). Trade-offs associated with dietary specialization in corallivorous butterflyfishes (Chaetodontidae: Chaetodon). Behavioral Ecology and Sociobiology 62, 989-994.

BlaCkBURN, T. M., GASTON, K. J. \& LODER, N. (1999). Geographic gradients in body size: a clarification of Bergmann's rule. Diversity and Distributions 5, 165-174.

Bonaldo, R. M., Hoey, A. S. \& Bellwood D. R. (2014). The ecosystem roles of parrotfishes on tropical reefs. Oceanography and Marine Biology: An Annual Review 52, 81-132.

Brown, J. H., Gillooly, J. F., Allen, A. P., Savage, V. M. \& West, G.B. (2004). Toward a metabolic theory of ecology. Ecology 85, 1771-1789.

Cavender-Bares, J., Kozak, K. H., Fine, P. V. A. \& Kembel, S. W. (2009). The merging of community ecology and phylogenetic biology. Ecology letters 12, $693-$ 715.

Cheung, W. W., Pitcher, T. J. \& Pauly, D. (2005). A fuzzy logic expert system to estimate intrinsic extinction vulnerabilities of marine fishes to fishing. Biological Conservation 124, 97-111. 
Choat, J. H., Klanten, O. S., van Herwerden, L., Robertson, D. R. \& Clements, K. D. (2012). Patterns and processes in the evolutionary history of parrotfishes (Family Labridae). Biological Journal of the Linnean Society 107, 529-557.

Clements, K. D. \& Knudsen, S. W. (2016). World-wide species distributions in the family Kyphosidae (Teleostei: Perciformes). Molecular Phylogenetics and Evolution 101, 252-266.

Cole, A. J., Pratchett, M. S. \& Jones, G. P. (2008). Diversity and functional importance of coral-feeding fishes on tropical coral reefs. Fish and Fisheries 9, 286307.

Connolly, S. R., MacNeil, M. A., CAley, M. J., Knowlton, N., CripPs, E., Hisano, M., Thibaut, L. M., Bhattacharya, B. D., Benedetti-Cecchi, L., Brainard, R. E., Brandt, A., Bulleri, F., Ellingsen, K. E., Kaiser, S., Kroncke, I. et al. (2014). Commonness and rarity in the marine biosphere. Proceedings of the National Academy of Sciences of the United States of America 111, 8524-8529.

Cooper, W. J., Carter, B. C., Conith, A. J., Rice, A. N. \& Westneat, M. W. (2017). The evolution of jaw protrusion mechanics has been tightly coupled to benthopelagic divergence in damselfishes (Pomacentridae). Journal of Experimental Biology (doi: 10.1242/jeb.143115).

Cooper, W. J., Smith, L. L. \& Westneat, M. W. (2009). Exploring the radiation of a diverse reef fish family: phylogenetics of the damselfishes (Pomacentridae), with new classifications based on molecular analyses of all genera. Molecular Phylogenetics and Evolution 52, 1-16.

CoOper, W. J. \& Westneat, M. W. (2009). Form and function of damselfish skulls: rapid and repeated evolution into a limited number of trophic niches. BMC Evolutionary Biology 9, 24.

COWMAN, P. F. (2014). Historical factors that have shaped the evolution of tropical reef fishes: a review of phylogenies, biogeography, and remaining questions. Frontiers in Genetics 5, 1-15.

Cowman, P. F. \& Bellwood, D. R. (2011). Coral reefs as drivers of cladogenesis: expanding coral reefs, cryptic extinction events, and the development of biodiversity hotspots. Journal of Evolutionary Biology 24, 2543-2562.

Cowman, P. F., Bellwood, D. R. \& van Herwerden, L. (2009). Dating the evolutionary origins of wrasse lineages (Labridae) and the rise of trophic novelty on coral reefs. Molecular Phylogenetics and Evolution 52, 621-631.

Cowman, P., Parravicini, V., Kulbicki, M. \& Floeter, S. R. (2017). The biogeography of tropical reef fishes: endemism and provinciality through time. Biological Reviews (doi:10.1111/brv.12323).

Craig, M. T. \& Hastings, P. A. (2007). A molecular phylogeny of the groupers of the subfamily Epinephelinae (Serranidae) with a revised classification of the tribe Epinephelini. Ichthyological Research 54, 1-17.

CRISP, M. D. \& COOK, L. G. (2009). Explosive radiation or cryptic mass extinction? Interpreting signatures in molecular phylogenies. Evolution 63, 2257-2265.

Davies, T. J., Smith, G. F., Bellstedt, D. U., BoAtwright, J. S., Bytebier, B., Cowling, R. M., et al. (2011). Extinction risk and diversification are linked in a plant biodiversity hotspot. PLoS Biology 9, e1000620. 
Diaz, S., CABIDO, M. \& CASANOves, F. (1998). Plant functional traits and environmental filters at a regional scale. Journal of Vegetation Science 9, 113-122.

Dornburg, A., Sidlauskas, B., Santini, F., Sorenson, L., Near, T. J. \& Alfaro, M. E. (2011). The influence of an innovative locomotor strategy on the phenotypic diversification of triggerfish (Family: Balistidae). Evolution 65, 1912-1926.

Duchene, D., Klanten, S. O., Munday, P. L., Herlen, J. \& Van Herwerden, L. (2013). Phylogenetic evidence for recent diversification of obligate coral-dwelling gobbies compared with their host corals. Molecular Phylogenetics and Evolution 69, 123-132.

Elliott, J. P. \& Bellwood, D. R. (2003). Alimentary tract morphology and diet in three coral reef fish families. Journal of Fish Biology 63, 1598-1609.

Erisman, B. E., Craig, M. T. \& Hastings, P. A. (2009). A phylogenetic test of the size advantage model: evolutionary changes in mating behavior influence the loss of sex change in a fish lineage. The American Naturalist 174, E83-E99.

Frédérich, B., FABri, G., Lepoint, G., VAndeWAlle, P. \& PARMEnTIER, E. (2009). Trophic niches of thirteen damselfishes (Pomacentridae) at the Grand Récif of Toliara, Madagascar. Ichthyological Research 56, 10-17.

Frédérich, B, Marramà, G., Carnevale, G., Santini, F. (2016). Non-reef environments impact the diversification of extant jacks, remoras and allies (Carangoidei, Percomorpha). Proceedings of the Royal Society of London Series B: Biological Sciences 283, 20161556.

Frédérich, B., Pilet, A., PArmentier, E. \& VAndewalle, P. (2008). Comparative trophic morphology in eight species of damselfishes (Pomacentridae). Journal of Morphology 269, 175-188.

Frédérich, B., Sorenson, L., SAntini, F., Slater, G. J. \& Alfaro, M. E. (2013). Iterative ecological radiation and convergence during the evolutionary history of damselfishes (Pomacentridae). The American Naturalist 181, 94-113.

FRÉDÉRICH, B. \& VANDEWALLE, P. (2011). Bipartite life cycle of coral reef fishes promotes increasing shape disparity of the head skeleton during ontogeny: an example from damselfishes (Pomacentridae). BMC Evolutionary Biology 11, 82.

Friedman, S. T., Price, S. A., Hoey, A. S. \& Wainwright, P. C. (2016). Ecomorphological convergence in planktivorous surgeonfishes. Journal of Evolutionary Biology 29, 965-978.

Gaither, M. R., Schultz, J. K., Bellwood, D. R., Pyle, R. L., DiBattista, J. D., RochA, L. A. \& Bowen, B. W. (2014). Evolution of pygmy angelfishes: Recent divergences, introgression, and the usefulness of color in taxonomy. Molecular Phylogenetics and Evolution 74, 38-47.

GASTON, K. J. \& BLACKBURN, T. M. (1996). Range size-body size relationships: evidence of scale dependence. Oikos 75, 479-485.

Gerhold, P., Cahill, J. F., Winter, M., Bartish, I. V \& Prinzing, A. (2015). Phylogenetic patterns are not proxies of community assembly mechanisms (they are far better). Functional Ecology 29, 600-614.

Goatley, C. H. R., Bellwood, D. R. \& Bellwood, O. (2010). Fishes on coral reefs: changing roles over the past 240 million years. Paleobiology 36, 415-427.

Gold, J. R., Voelker, G. \& Renshaw, M. A. (2011). Phylogenetic relationships of tropical western Atlantic snappers in subfamily Lutjaninae (Lutjanidae: Perciformes) 
inferred from mitochondrial DNA sequences. Biological Journal of the Linnean Society 102, 915-929.

Guillemot, N., Kulbicki, M., Chabanet, P. \& Vigliola, L. (2011). Functional redundancy patterns reveal non-random assembly rules in a species-rich marine assemblage. PLoS ONE 6, e26735.

HALPERN, B. S. \& FLOETER, S. R. (2008). Functional diversity responses to changing species richness in reef fish communities. Marine Ecology Progress Series 364, $147-$ 156.

HARMELIN-Vivien, M. L. (2002). Energetics and fish diversity on coral reefs. Coral reef fishes: dynamics and diversity on a complex ecosystem (ed. P. F. Sale), pp. 265-274. Academic Press, San Diego.

Harmon, L. J., Losos, J. B., Davies, J. T., Gillespie, R. G., GitTleman, J. L., Jennings, B. W., KozaK, K. H., McPeek, M. A., Moreno-Roark, F., Near, T. J., Purvis, A., Ricklefs, R. E., Schluter, D., Schulte II, J. A., SEehausen, O., Sidlauskas, B. L., Torres-Carvajal, O., Weir, J. T. \& Mooers, A. Ø. (2010). Early bursts of body size and shape evolution are rare in comparative data. Evolution 64, 2385-2396.

Harmon, L. J., Schulte, J. A., Larson, A. \& Losos, J. B. (2003). Tempo and mode of evolutionary radiation in iguanian lizards. Science 301, 961-964.

Harmon, L. J., Weir, J. T., Brock, C. D., Glor, R. E. \& Challenger, W. (2008). Geiger: investigating evolutionary radiations. Bioinformatics 24, 129-131.

Hodge, J. R. \& Bellwood, D. R. (2015). On the relationship between species age and geographical range in reef fishes: are widespread species older than they seem? Global Ecology and Biogeography 24, 495-505.

Hodge, J. R. \& Bellwood, D. R. (2016). The geography of speciation in coral reef fishes: the relative importance of biogeographical barriers in separating sisterspecies. Journal of Biogeography 43, 1324-1335.

Hodge, J. R., ReAd, C. I., VAN HERWERden, L. \& Bellwood, D. R. (2012). The role of peripheral endemism in species diversification: Evidence from the coral reef fish genus Anampses (Family: Labridae). Molecular Phylogenetics and Evolution 62, 653-663.

Hoey, A. S. \& BelLwood, D. R. (2008). Cross-shelf variation in the role of parrotfishes on the Great Barrier Reef. Coral Reefs 27, 37-47.

Holmlund, C. M. \& Hammer, M. (1999). Ecosystem services generated by fish populations. Ecological Economics 29, 253-268.

Hooper, D. U., Solan, M., Symstad, A. J., Díaz, S., Gessner, M. O. \& Buchmann, N. (2002). Species diversity, functional diversity and ecosystem functioning. Biodiversity and Ecosystem Functioning: Syntheses and Perspectives (eds M. Loreau, S. Naeem and P. Inchausti), pp. 195- 208. Oxford University Press, Oxford. HowE, J. C. (1993). A comparative analysis of the feeding apparatus in pomacanthids, with special emphasis of oesiphageal papillae in Genicanthus personatus. Journal of Fish Biology 43, 593-602.

Hubert, N., Paradis, E., Bruggemann, H. \& Planes, S. (2011). Community assembly and diversification in Indo-Pacific coral reef fishes. Ecology and Evolution 1, 22977. 
Hughes, T. P., Bellwood, D. R., Connolly, S. R., Cornell, H. V. \& Karlson, R. H. (2014). Double jeopardy and global extinction risk in corals and reef fishes. Current Biology 24, 2946-2951.

JABLONSKI, D. (2008). Species selection: theory and data. Annual Review of Ecology, Evolution, and Systematics 39, 501-524.

JABLONSKI, D. \& SEPKOSKI, J. J. (1996). Paleobiology, community ecology, and scales of ecological pattern. Ecology 77, 1367-1378.

JoHnson, K. G., JACKSON, J. B. C. \& BUDD, A. F. (2008). Caribbean reef development was independent of coral diversity over 28 million years. Science 319, 1521-1523.

Kazancioglu, E., Near, T. J., Hanel, R. \& Wainwright, P. C. (2009). Influence of sexual selection and feeding functional morphology on diversification rate of parrotfishes (Scaridae). Proceedings of the Royal Society B: Biological Sciences 276, 3439-3446.

Konow, N. \& Bellwood, D. R. (2005). Prey-capture in Pomacanthus semicirculatus (Teleostei, Pomacanthidae): functional implications of intramandibular joints in marine angelfishes. The Journal of Experimental Biology 208, 1421-1433.

KonOw, N. \& BELLWOOD, D. R. (2011). Evolution of high trophic diversity based on limited functional disparity in the feeding apparatus of marine angelfishes (f. Pomacanthidae). PLOS ONE 6, e24113.

Kraft, N. J. B., Cornwell, W. K., WebB, C. O. \& Ackerly, D. D. (2007). Trait evolution, community assembly, and the phylogenetic structure of ecological communities. The American Naturalist 170, 271-283.

KUITER, R. H. (2002). Butterflyfishes, Bannerfishes and Their Relatives: A Comprehensive Guide to Chaetodontidae and Microcanthidae. TMC Publishing, Chorleywood.

KULbicki, M., Bozec, Y. M. \& GreEn, A. (2005). Implications of biogeography in the use of butterflyfishes (Chaetodontidae) as indicators for Western and Central Pacific areas. Aquatic Conservation: Marine and Freshwater Ecosystems 15, S109-S126.

Kulbicki, M., Parravicini, V. \& Mouillot, D. (2015). Patterns and processes in reef fish body size. Ecology of Fishes on Coral Reefs (ed. C. Mora), pp. 104-115. Cambridge University Press, Cambridge.

LABARBERA, M. (1989). Analyzing body size as a factor in ecology and evolution. Annual Review of Ecology and Systematics 20, 97-117.

LAUDER, G. V. (1982). Patterns of evolution in the feeding mechanism of Actinopterygian fishes. American Zoologist 22, 275-285.

Leprieur, F., Colosio, S., Descombes, P., Parravicini, V., Kulbicki, M., Cowman, P. F., Bellwood, D. R., Mouillot, D. \& Pellissier L. (2016). Historical and contemporary determinants of global phylogenetic structure in tropical reef fish faunas. Ecography 39, 825-835.

Litsios, G., Pearman, P. B., LanterbecQ, D., Tolou, N. \& Salamin, N. (2014). The radiation of the clownfishes has two geographical replicates. Journal of Biogeography, 41, 2140-2149.

Litsios, G., Sims, C. A., WÜest, R. O., Pearman, P. B., Zimmermann, N. E. \& SAlamin, N. (2012). Mutualism with sea anemones triggered the adap- tive radiation 
of clownfishes. BMC Evolutionary Biology 12, 212.

Lobato, F. L., Barneche, D. R., Siqueira, A. C., Liedke, A. M. R., Lindner, A., Pie, M. R., Bellwood, D. R. \& Floeter, S. R. (2014). Diet and diversification in the evolution of coral reef fishes. PLoS ONE 9, e102094.

Loreau, M., Naeem, S., Inchausti, P., Bengtsson, J., Grime, J. P., Hector, A., Hooper, D. U., Huston, M. A, Raffaelli, D., Schmid, B., Tilman, D. \& Wardle D. A. (2001). Biodiversity and ecosystem functioning: current knowledge and future challenges. Science 294, 804-808.

Losos, J. B. (2008). Phylogenetic niche conservatism, phylogenetic signal and the relationship between phylogenetic relatedness and ecological similarity among species. Ecology Letters 11, 995-1003.

Losos, J. B. (2011). Convergence, adaptation, and constraint. Evolution 65, 1827-1840. Luiz, O. J., Allen, A. P., Robertson, D. R., Floeter, S. R., Kulbicki, M., Vigliola, L., BECHELER, R. \& MADIN, J. S. (2013). Adult and larval traits as determinants of geographic range size among tropical reef fishes. Proceedings of the National Academy of Sciences of the United States of America 110, 16498-16502.

Ma, K. Y., Craig, M. T., ChOAt, J. H. \& VAn Herwerden, L. (2016). The historical biogeography of groupers: Clade diversification patterns and processes. Molecular Phylogenetics and Evolution 100,21-30.

McCord, C. L. \& Westneat, M. W. (2016). Evolutionary patterns of shape and functional diversification in the skull and jaw musculature of triggerfishes (Teleostei: Balistidae). Journal of Morphology 277, 737-752.

McGill, B. J., Enquist, B. J., Weiner, E. \& Westoby, M. (2006). Rebuilding community ecology from functional traits. Trends in Ecology and Evolution 21, 178185.

Micheli, F., De Leo, G., Butner, C., Martone, R. G. \& Shester, G. (2014). A riskbased framework for assessing the cumulative impact of multiple fisheries. Biological Conservation 176, 224-235.

Miller, T. L. \& CRIBB, T. H. (2007). Phylogenetic relationships of some common IndoPacific snappers (Perciformes: Lutjanidae) based on mitochondrial DNA sequences, with comments on the taxonomic position of the Caesioninae. Molecular Phylogenetics and Evolution 44, 450-460.

Mora, C., Treml, E., Robert, J., Crosby, K., Roy, D. \& Tittensor, D. P. (2012). High connectivity among habitats precludes the relationship between dispersal and range size in tropical reef fishes. Ecography 35, 89-96.

Mouillot, D., Graham, N. A. J., Villéger, S., Mason, N. W. H. \& Bellwood, D. R. (2013). A functional approach reveals community responses to disturbances. Trends in Ecology and Evolution 28, 167-177.

Mouillot, D., Villéger, S., Parravicini, V., Kulbicki, M., Arias-GonzÁlez, J. E., Bender, M., Chabanet, P., Floeter, S. R., Friedlander, A., Vigliola, L. \& BELLwOOD, D. R. (2014). Functional over-redundancy and high functional vulnerability in global fish faunas of tropical reefs. Proceedings of the National Academy of Sciences of the United States of America 111, 13757-13762. 
Near, T. J., Dornburg, A., Eytan, R. I., Keck, B. P., Smith, W. L., Kuhn, K. L., Moore, J. A., Price, S. A., Burbrink, F. T., Friedman, M. \& Wainwright, P. C. (2013). Phylogeny and tempo of diversification in the superradiation of spiny-rayed fishes. Proceedings of the National Academy of Sciences of the United States of America 110, 12738-12743.

O’Dea, A., Jackson, J. B. C., Fortunato, H., Smith, J. T., D’Croz, L., Johnson, K. G. \& TodD, J. A. (2007). Environmental change preceded Caribbean extinction by 2 million years. Proceedings of the National Academy of Sciences of the United States of America 104, 5501-5506.

Olden, J. D., Hogan, Z. S. \& Zanden, M. J. V. (2007). Small fish, big fish, red fish, blue fish: size-biased extinction risk of the world's freshwater and marine fishes. Global Ecology and Biogeography 16, 694-701.

Ottimofiore, E., Albouy, C., Leprieur, F., Descombes, P., Kulbicki, M., Mouillot, D., Parravicini, V. \& Pellissier, L. (2017). Responses of coral reef fishes to past climate changes are related to life-history traits. Ecology and Evolution (doi: 10.1002/ece3.2800).

Paradis, E., Claude, J. \& Strimmer, K. (2004). APE: Analyses of Phylogenetics and Evolution in R language. Bioinformatics 20, 289-290.

PARENTI, P. \& RANDAll, J. E. (2011). Checklist of the species of the families Labridae and Scaridae : an update. Smithiana Bulletin 13, 29-44.

Parravicini, V., Villéger, S., McClanahan, T., Arias-Gonzales, J. E., Bellwood, D. R., Belmaker, J., Chabanet, P., Floeter, S. R., Friedlander, A., Guilhaumon, F., Vigliola, L., Kulbicki, M. \& Mouillot, D. (2014). Global mismatch between species richness and vulnerability of reef fish assemblages. Ecology Letters 17, 1101-1110.

Pellissier, L., Leprieur, F., Parravicini, V., Litsios, G., Olesen, S., Wisz, M. S., Kulbicky, M., Cowman, P., Bellwood, D. \& Mouillot, D. (2014). Quaternary coral reef refugia preserved fish diversity. Science 344, 1016-1019.

Peres-Neto, P. R. (2004). Patterns in the co-occurrence of stream fish metacommunties: the role of site suitability, morphology and phylogeny versus species interactions. Oecologia 140, 352-360.

Peters, R. H. (1986). Ecological implications of body size. Cambridge University Press, Cambridge.

Pratchett, M. S., Berumen, M. L. \& Kapoor, B. G. (2014). Biology of Butterflyfishes. CRC Press, Boca Raton.

Price, S. A., Claverie, T., Near, T. J. \& Wainwright, P. C. (2015) Phylogenetic insights into the history and diversification of fishes on reefs. Coral reefs $\mathbf{3 4}, 997-$ 1009.

Price, S. A., Holzman, R., Near, T. J. \& Wainwright, P. C. (2011). Coral reefs promote the evolution of morphological diversity and ecological novelty in labrid fishes. Ecology Letters 14, 462-469.

Price, S. A., Schmitz, L., Oufiero, C. E., Eytan, R. I., Dornburg, A., Smith, W. L., Friedman, M., Near, T. J. \& Wainwright, P. C. (2014). Two waves of colonization 
straddling the K-Pg boundary formed the modern reef fish fauna. Proceedings of the Royal Society of London Series B: Biological Sciences 281, 20140321.

Price, S. A., TAVera, J. J., Near, T. J. \& Wainwright, P. (2013). Elevated rates of morphological and functional diversification in reef dwelling haemulid fishes. Evolution 67, 417-428.

Puebla, O., Bermingham, E., Guichard, F. \& Whiteman, E. (2007). Colour pattern as a single trait driving speciation in Hypoplectrus coral reef fishes? Proceedings of the Royal Society of London Series B: Biological Sciences 274, 1265-1271.

Rabosky, D. L., Santini, F., Eastman, J., Smith, S. A., Sidlauskas, B., Chang, J. \& Alfaro, M. E. (2013). Rates of speciation and morphological evolution are correlated across the largest vertebrate radiation. Nature Communications 4, 1958.

RANDALl J. E. (1967). Food habits of reef fishes of the West Indies. Studies in Tropical Oceanography 5, 665-847.

Read, C. I., Bellwood, D. R. \& VAn Herwerden, L. (2006). Ancient origins of IndoPacific coral reef fish biodiversity: A case study of the leopard wrasses (Labridae: Macropharyngodon). Molecular Phylogenetics and Evolution 38, 808-819.

Reich, P. B., Wright, I. J., CAVender-Bares, J., Craine, J. M., Oleksyn, J., Westoby, M., \& Walters, M. B. (2003). The evolution of plant functional variation: traits, spectra, and strategies. International Journal of Plant Sciences 164, S143-S164.

Reynolds, J. D., Dulvy, N. K., Goodwin, N. B., \& Hutchings, J. A. (2005). Biology of extinction risk in marine fishes. Proceedings of the Royal Society of London B: Biological Sciences 272, 2337-2344.

Reynolds, J. D., Jennings, S. \& Dulvy, N. K. (2001). Life histories of fishes and population responses to exploitation. In Conservation of Exploited Species (eds J.D. Reynolds, G.M. Mace, K.H. Redford and J.G. Robinson), pp. 147-168. Cambridge University Press, Cambridge, UK.

RICKLEFS, R. E. (2010). Evolutionary diversification, coevolution between populations and their antagonists, and the filling of niche space. Proceedings of the National Academy of Sciences of the United States of America 107, 1265-1272.

Rowe, K. C., Aplin, K. P., BAverstock, P. R. \& Moritz, C. (2011). Recent and rapid speciation with limited morphological disparity in the genus Rattus. Systematic Biology 60, 188-203.

Ruttenberg, B. I. \& Lester, S. E. (2015). Patterns and processes in geographic range size in coral reef fishes. Ecology of Fishes on Coral Reefs (ed. C. Mora), pp. 97-103. Cambridge University Press, Cambridge.

Santini, F., Carnevale, G. \& Sorenson, L. (2015). First timetree of Sphyraenidae (Percomorpha) reveals a Middle Eocene crown age and an Oligo-Miocene radiation of barracudas. Italian Journal of Zoology 82, 133-142.

Santini, F., Nguyen, M. T. T., Sorenson, L., WaltzeK, T. B., Lynch Alfaro, J. W., Eastman, J. M. \& Alfaro, M. E. (2013a). Do habitat shifts drive diversification in teleost fishes? An example from the pufferfishes (Tetraodontidae). Journal of Evolutionary Biology 26, 1003-1018. 
Santini, F., Sorenson, L. \& Alfaro, M. E. (2013b). A new multi-locus timescale reveals the evolutionary basis of diversity patterns in triggerfishes and filefishes (Balistidae, Monacanthidae; Tetraodontiformes). Molecular Phylogenetics and Evolution 69, 165-176.

SAntini, F., Sorenson, L. \& Alfaro, M. E. (2016). Phylogeny and biogeography of hogfishes and allies (Bodianus, Labridae). Molecular Phylogenetics and Evolution 99, 1-6.

Siqueira, A. C., Oliveira-Santos, L. G. R., Cowman, P. F. \& Floeter, S. R. (2016). Evolutionary processes underlying latitudinal differences in reef fish biodiversity. Global Ecology and Biogeography, DOI: 10.1111/geb.12506.

Slater, G. J., Price, S. A., SAntini, F. \& Alfaro, M. E. (2010). Diversity versus disparity and the radiation of modern cetaceans. Proceedings of the Royal Society of London B: Biological Sciences 277, 3097-3104.

Sorenson, L., SANTini, F. \& Alfaro, M. E. (2014). The effect of habitat on modern shark diversification. Journal of Evolutionary Biology 27, 1536-1548.

Stuart-Smith, R. D., Bates, A. E., Lefcheck, J. S., Duffy, J. E., BAKer, S. C., Thomson, R. J., Stuart-Smith, J. F., Hill, N. A., Kininmonth, S. J., Airoldi, L., Becerro, M. A., Campbell, S. J., Dawson, T. P., Navarrete, S. A., Soler, G. A., Strain, E. M., WiLlis, T. J. \& EdGAR, G. J. (2013). Integrating abundance and functional traits reveals new global hotspots of fish diversity. Nature 501, 539-542

Swenson, N. G., Enquist, B. J., Pither, J., Thompson, J. \& Zimmerman, J. K. (2006). The problem and promise of scale dependency in community phylogenetics. Ecology 87, 2418-2424.

Tavera, J. J., Acero, A. P., Balart, E. F. \& Bernardi, G. (2012) Molecular phylogeny of grunts (Teleostei, Haemulidae), with an emphasis on the ecology, evolution, and speciation history of New World species. BMC Evolutionary Biology $12,57$.

Tilman, D. (2001). Functional diversity. Encyclopedia of Biodiversity (ed. S.A. Levin), pp. 109-120. Academic Press, San Diego, CA.

Tilman, D., Knops, J., Wedin, D., Reich, P., Ritchie, M. \& Siemann, E. (1997). The influence of functional diversity and composition on ecosystem processes. Science 277, 1300-1302.

VERMEIJ, G. J. (1977). The Mesozoic marine revolution: evidence from snails, predators and grazers. Paleobiology 3, 245-258.

Violle, C., Navas, M. L., Vile, D., Kazakou, E., Fortunel, C., Hummel, I. \& GARNIER, E. (2007). Let the concept of trait be functional! Oikos 116, 882-892.

Violle, C., Reich, P. B., Pacala, S. W., Enquist, B. J. \& Kattge, J. (2014). The emergence and promise of functional biogeography. Proceedings of the National Academy of Sciences of the United States of America 111, 13690-13696.

Wainwright, P. C., Bellwood, D. R., Westneat, M. W., Grubich, J. R. \& Hoey, A. S. (2004). A functional morphospace for the skull of labrid fishes: Patterns of diversity in a complex biomechanical system. Biological Journal of the Linnean Society 82, 1-25. 
Wainwright, P. C., Smith, W. L., Price, S. A., Tang, K. L., Ferry, L. A, Sparks, J. S. \& NEAR, T. J. (2012). The evolution of pharyngognathy: a phylogenetic and functional appraisal of the pharyngeal jaw key innovation in labroid fishes and beyond. Systematic Biology 61, 1001-1027.

WALKER, B., KINZIG, A. \& LANGRIDGE, J. (1999). Plant attribute diversity, resilience, and ecosystem function: The nature and significance of dominant and minor species. Ecosystems 2, 95-113.

Wallace, C. C. \& Rosen, B. (2006). Diverse staghorn corals (Acropora) in highlatitude Eocene assemblages: implications for the evolution of modern diversity patterns of reef corals. Proceedings of the Royal Society of London B: Biological Sciences 273, 975-982.

WeBB, C. O. (2000). Exploring the phylogenetic structure of ecological communities: an example for rain forest trees. The American Naturalist 156: 145-155.

Webb, C. O., Ackerly, D. D., McPeek, M. A. \& Donoghue, M. J. (2002). Phylogenies and community ecology. Annual Review of Ecology and Systematics 33, 475-505.

WESTNEAT, M. W. (1995). Feeding, function, and phylogeny: analysis of historical biomechanics in labrid fishes using comparative methods. Systematic Biology 44, $361-383$.

Westneat, M. W. \& Alfaro, M. E. (2005). Phylogenetic relationships and evolutionary history of the reef fish family Labridae. Molecular Phylogenetics and Evolution 36, 370-90.

Westneat, M. W., Alfaro, M. E., Wainwright, P. C., Bellwood, D. R., Grubich, J. R., Fessler, J. L., Clements, K. D. \& SMith, L. L. (2005). Local phylogenetic divergence and global evolutionary convergence of skull function in reef fishes of the family Labridae. Proceedings of the Royal Society of London B: Biological Sciences 272, 993-1000.

WeStOBY, M. \& Wright, I. J. (2006). Land-plant ecology on the basis of functional traits. Trends in Ecology \& Evolution 21, 261-268.

White, E. P., ERnest, S. K. M., Kerkhoff, A. J. \& EnQuist, B. J. (2007). Relationships between body size and abundance in ecology. Trends in Ecology and Evolution 22, 323-330.

WiENS, J. J. \& GRAHAM C. H. (2005). Niche conservatism: integrating evolution, ecology, and conservation biology. Annual review of ecology, evolution, and systematics 36, 519-539.

WINEMILLER, K. O. (1991). Ecomorphological diversification in lowland freshwater fish assemblages from five biotic regions. Ecological Monographs 61, 343-365.

Winemiller, K. O., FitzGerald, D. B., Bower, L. M. \& Pianka, E. R. (2015). Functional traits, convergent evolution, and periodic tables of niches. Ecology Letters 18, 737-751.

WooD, R. (1999). Reef Evolution. Oxford University Press, Oxford. 


\section{Figure Legends}

Fig. 1. Diet and feeding mode reconstruction mapped on a time-calibrated phylogenetic tree for 303 (of $\sim 630$ ) species of wrasses and parrotfishes (family Labridae) (Cowman \& Bellwood, 2011 combined with Choat et al., 2012). Colour-coding depicts different feeding modes of adults. The timescale is dated in million years (Myr) before present. Pie graphs within symbols represent the probability of the ancestral state in each node. Clade abbreviations: Hyp, Hypsigenyines; Lb, Labrines; Chl, Cheilines; Scr, Scarines; Cirr, Cirrhilabrus; Lbr, Labrichthyines; Mcr, Macropharyngodon. Reconstruction was conducted using maximum likelihood in Ape package (Paradis et al., 2004), R software. Fish images: J.P. Krajewski, J.E. Randall, and L.A. Rocha.

Fig. 2. Reconstruction of coral feeding in a time-calibrated phylogenetic tree for 95 (of 127) species of butterflyfishes and bannerfishes (family Chaetodontidae) (Cowman \& Bellwood, 2011). Colour-coding is related to species diets. The timescale is dated in million years (Myr) before present. Pie graphs within symbols represent the probability of the ancestral state in each node. Clade abbreviations: Bn, bannerfishes; Pr, Prognathodes; C1, 2, 3 \& 4, Chaetodon. Reconstruction was conducted using maximum likelihood in Ape package (Paradis et al., 2004), R software. Images from Kuiter (2002).

Fig. 3. Three examples of independent transitions to planktivory in reef fish lineages. Note that specializations for feeding in mid-water on zooplankton, such as a slender fusiform body, and a deeply forked caudal fin represent departures from the typical morphology of the genus. Trees used: Bodianus clade (Santini et al., 2016), Kyphosus (Clements \& Knudsen, 2016) and Cephalopholis clade (Ma et al., 2016).

Fig. 4. Reconstruction of water column use on a time-calibrated phylogenetic tree for 206 (of 373) damselfish species (family Pomacentridae) (Frédérich et al., 2013). Pie graphs within symbols represent the probability of the ancestral state (position in the water column) at each node, with colour-coding representing fish species that live close to the bottom (blue), and fish that generally form aggregations well above the bottom to feed on zooplankton (red). The timescale is dated in million years (Myr) before present. 
1342 Reconstruction was conducted using maximum likelihood in Ape package (Paradis et al., 2004), R software. Fish pictures: J.P. Krajewski and L. Tyk.

Fig. 5. Reconstruction of body size on a time-calibrated phylogenetic tree for 303 species of wrasses and parrotfishes (family Labridae) (Cowman \& Bellwood, 2011 combined with Choat et al., 2012). The colour gradient represents variation in species body size, from small to large body sizes (blue to red shades). Body size values were log-transformed prior to reconstruction. Pictures are representative of those fish species larger than $80 \mathrm{~cm}$ or smaller than $8 \mathrm{~cm}$ in length. The timescale is dated in million years (Myr) before present. Reconstruction was conducted using maximum likelihood in Ape package (Paradis et al., 2004), R software. Fish pictures: J.P. Krajewski, J.E. Randall, and L.A. Rocha.

Fig. 6. Reconstruction of range size (given by the number of grid cells of $550 \times 550 \mathrm{~km}$ ) in a time-calibrated phylogenetic tree for the Labridae (Cowman \& Bellwood, 2011 combined with Choat et al., 2012). Colour-coding represents a gradient from 1 to 258 occupied grid cells. The timescale is dated in million years (Myr) before present. Reconstruction was conducted using maximum likelihood in Ape package (Paradis et al., 2004), R software. Pictures of representative fish with large and small range sizes are shown. Fish pictures: J.P. Krajewski, J.E. Randall, and L.A. Rocha.

Fig. 7. Maps of geographical ranges of sister species that present disparate sizes. Range data comes from IUCN database. Maps are shown in Mollweide projection.

Fig. 8. The relationship between age and range size across 303 Labridae species, divided into (A) Indo-Pacific plus Tropical Eastern Pacific (TEP) and (B) Atlantic Ocean basins. There was no significant relationship between all species ages and their geographic range. $(\mathrm{C}, \mathrm{D})$ The relationship between minimum geographic range and lineage age of species sister pairs for the same two regions, in an approach to account for peripheral isolation processes (Hodge \& Bellwood, 2016). A significant relationship was found between log minimum range size and log lineage age of sister pairs, with a significant effect linked to ocean basin differences $\left(r^{2}=0.18 ; N=191\right.$; d.f. $=2,188$; $F=20.9 ; P<0.001)$. Circles are proportional to species maximum body size and colourcoding represents feeding modes. 
1377 Fig. 9. Multi-trait patterns through time for the families Labridae, Pomacentridae and 1378 Chaetodontidae. (A) Lineage through time (LTT) plot displaying the log number of 1379 lineages arising through time. LTT plots were constructed from the time-calibrated 1380 phylogenies displayed in Figs 1, 2 and 4 (see text for details). Eo, Eocene; Oli, 1381 Oligocene; Mio, Miocene; PP, . (B) Stacked density plot of ancestral trait reconstructions reflecting trophic evolution in the family Labridae; water column use in the family Pomacentridae; and corallivory in the family Chaetodontidae. For the Labridae, feeding modes are reclassified as generalist modes (Gen: general carnivory, piscivory, omnivory), herbivory and detritivory (H/D: browsing, scraping, excavating) and specialized feeding modes (Spec: coral mucous feeding, obligate cleaning, foraminifera feeding and planktivory). In the Chaetodontidae node density plot, nodes that are reconstructed as corallivores contain both hard- and soft-coral-feeding lineages. (C) Mean subclade disparity through time (DTT) for body size data (solid line) for each of the focal families. The dashed line indicates the median subclade DTT based on 1,000 simulations of character evolution on each reef fish family phylogeny under Brownian motion. The shaded area indicates the 95\% DTT range for the simulated data. Body sizes were log-transformed prior to analyses. (D) Mean subclade disparity through time (DTT) for range size (solid line) for each family. Ranges size is calculated as the number of $550 \times 550 \mathrm{~km}$ grid cells occupied by each species. As for body size disparity seen in $\mathrm{C}$, the dashed line indicates the median and the shaded area the 95\% DTT range based on 1,000 simulations under Brownian motion. DTT analyses were conducted in R using functions from the Geiger package (Harmon et al., 2008). For both body size and range size disparity, we calculated the disparity index (DI), which quantifies the relative disparity of a clade compared with the expectation under the null Brownian motion model (see Harmon et al., 2003). Positive DI values indicate higher disparity than expected under the null model.

Fig. 10. A framework for trait-based approaches to studies of ecological communities coupled with phylogenies (or phylogenetic data) and abundance data. The phylogeny on the left corresponds to a hypothetical regional pool of species and the phylogenies on the right represent the local structure of communities (C1, C2, C3 and C4). Each structure reveals the effect of different mechanisms over spatial and temporal scales on 
1409 the regional pool of species (see text for further information). Different coloured and/or 1410 shaped fish depict the presence of different traits.

1411

1412

1413

1414

1415

1416

1417

1418

1419

1420

1421

1422

1423

1424

1425

1426

1427

1428

1429

1430

1431

1432

1433

1434

1435

1436

1437

1438

1439

1440

1441

1442 
Figure 1

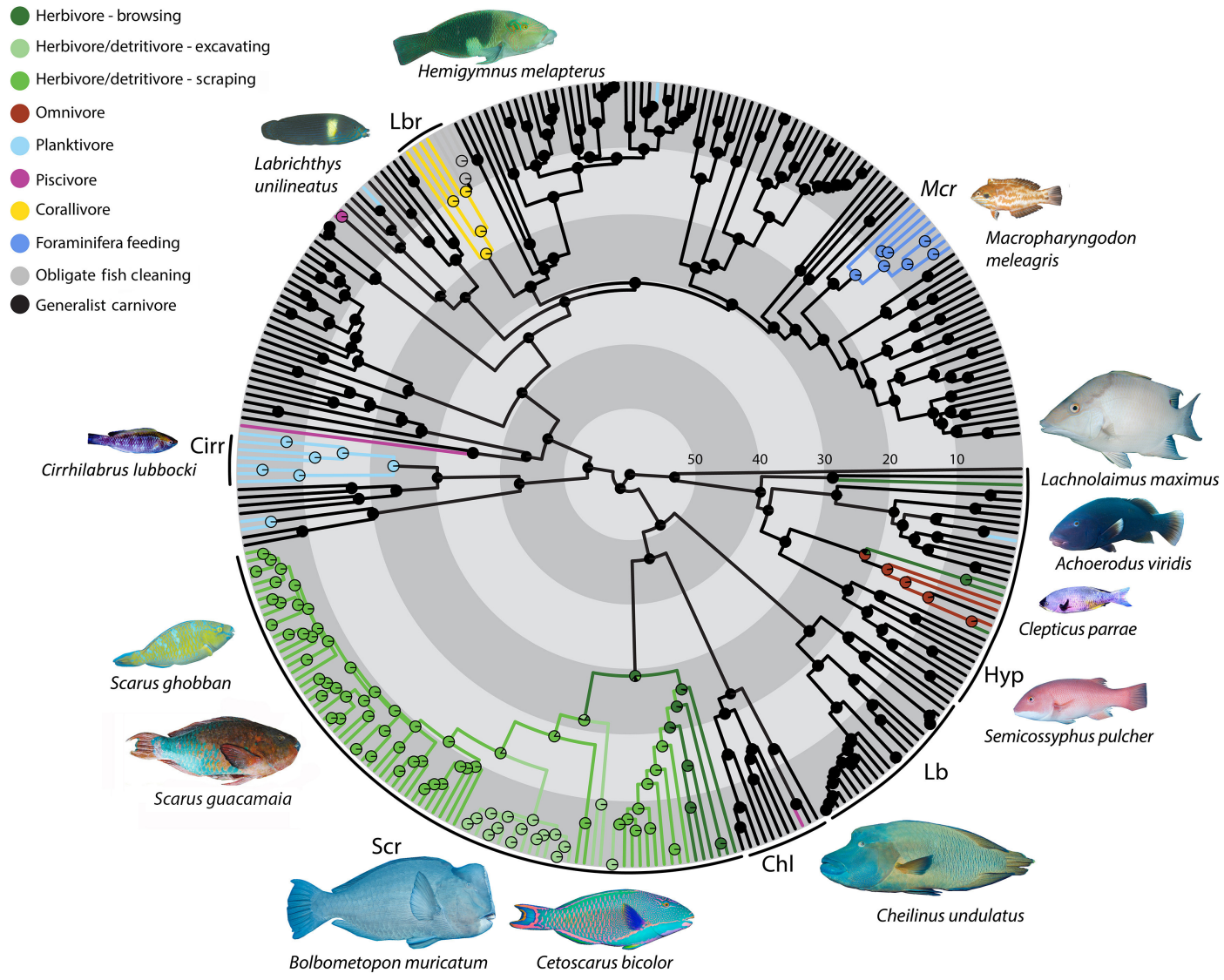

1446 Figure 2

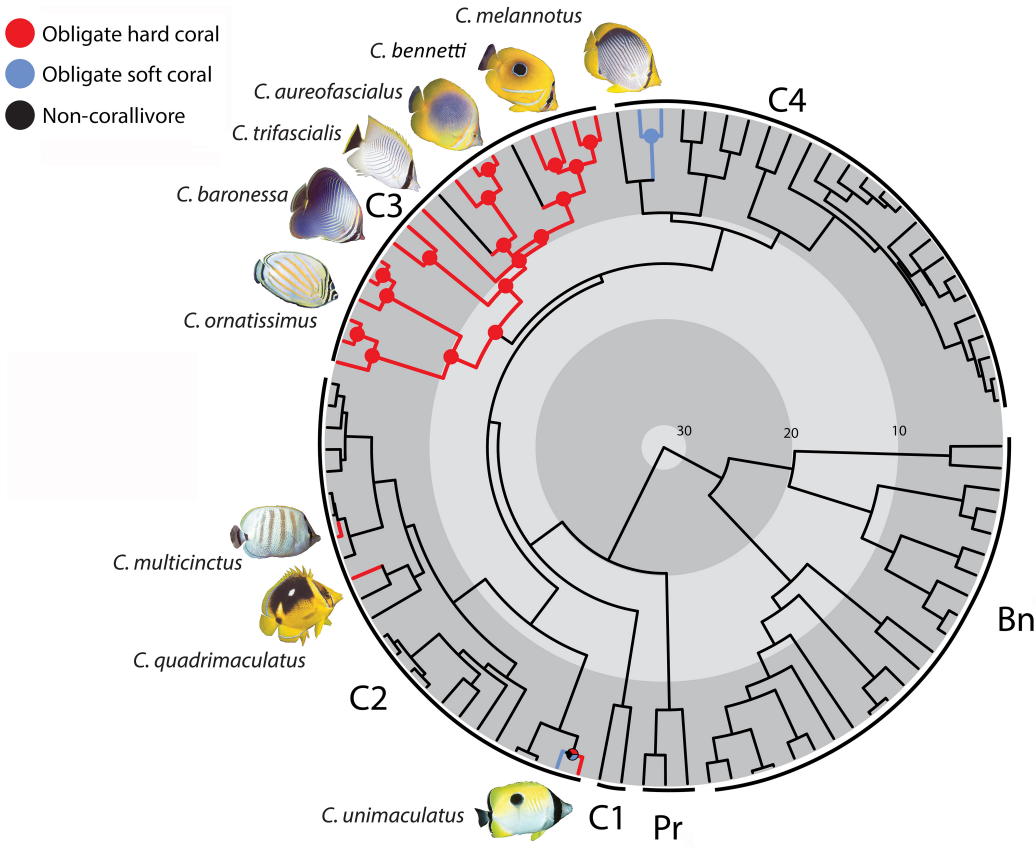


Figure 3

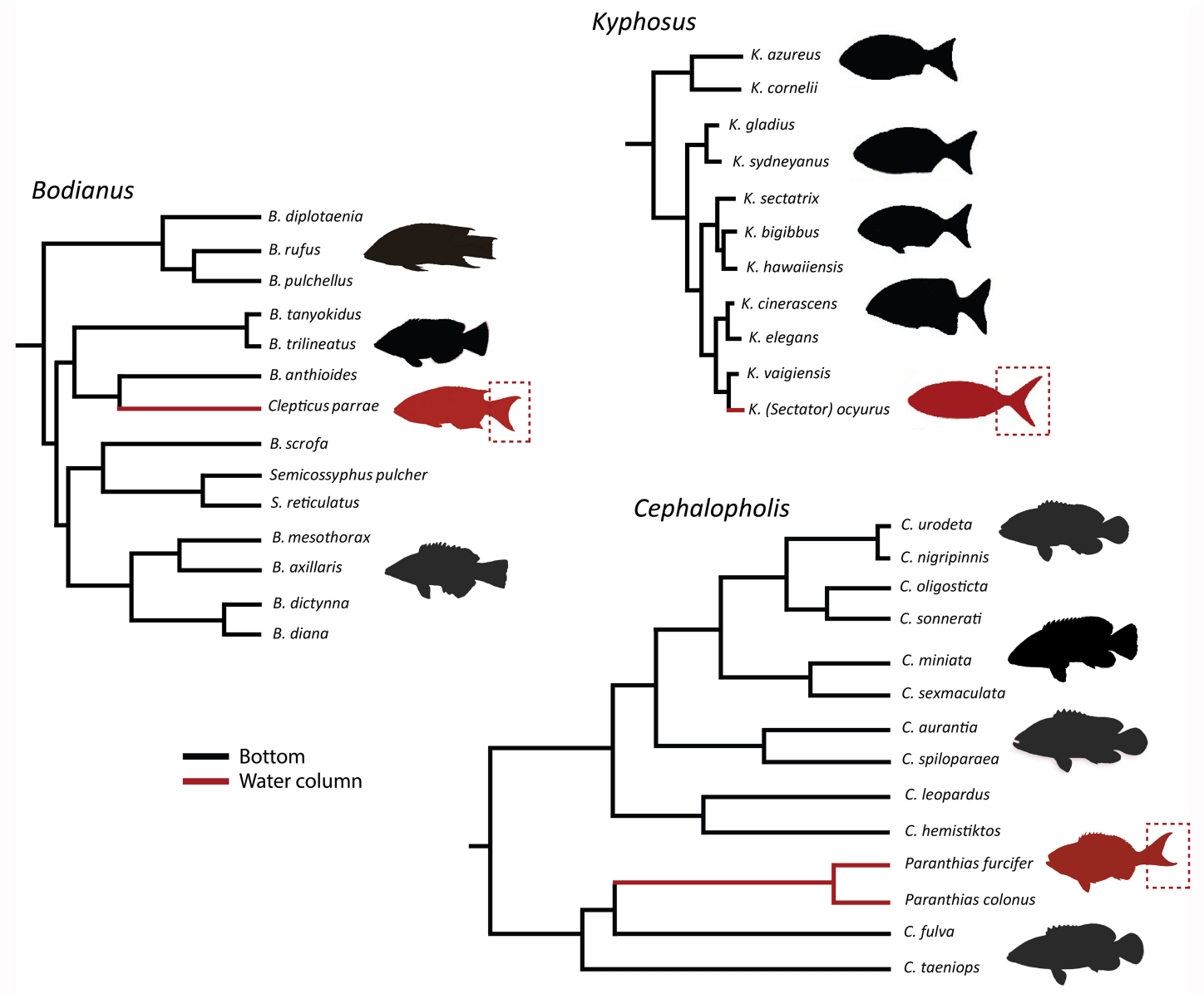

1450

1451

1452

1453 
1467 Figure 4

1468

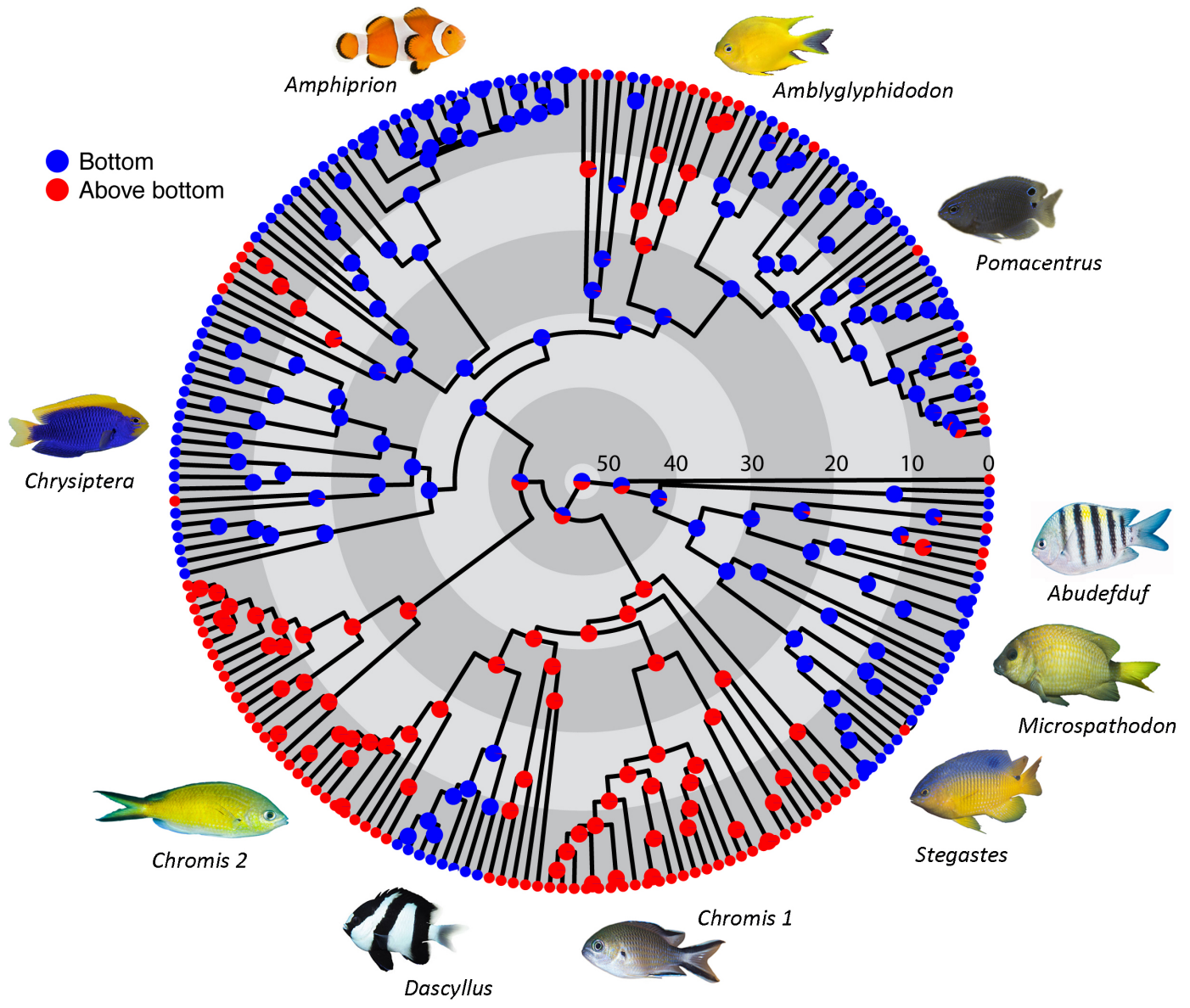

1469

1470

1471

1472

1473

1474

1475

1476

1477

1478

1479

1480 
1484

1485

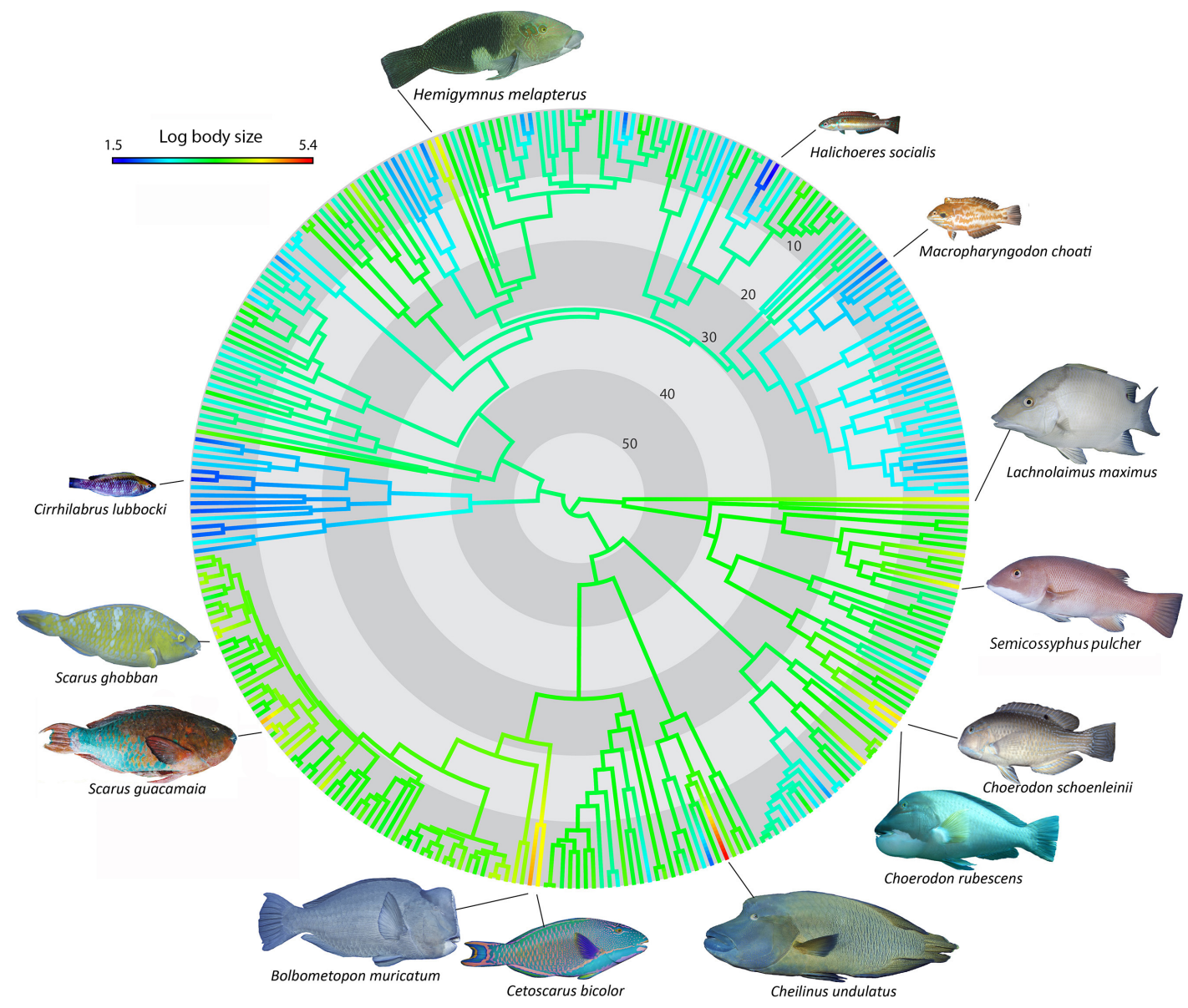

1486 
1501

1502

1503

1504

1505

1506

1507

1508

1509

1510

1511

1512

1513

1514

1515

1516

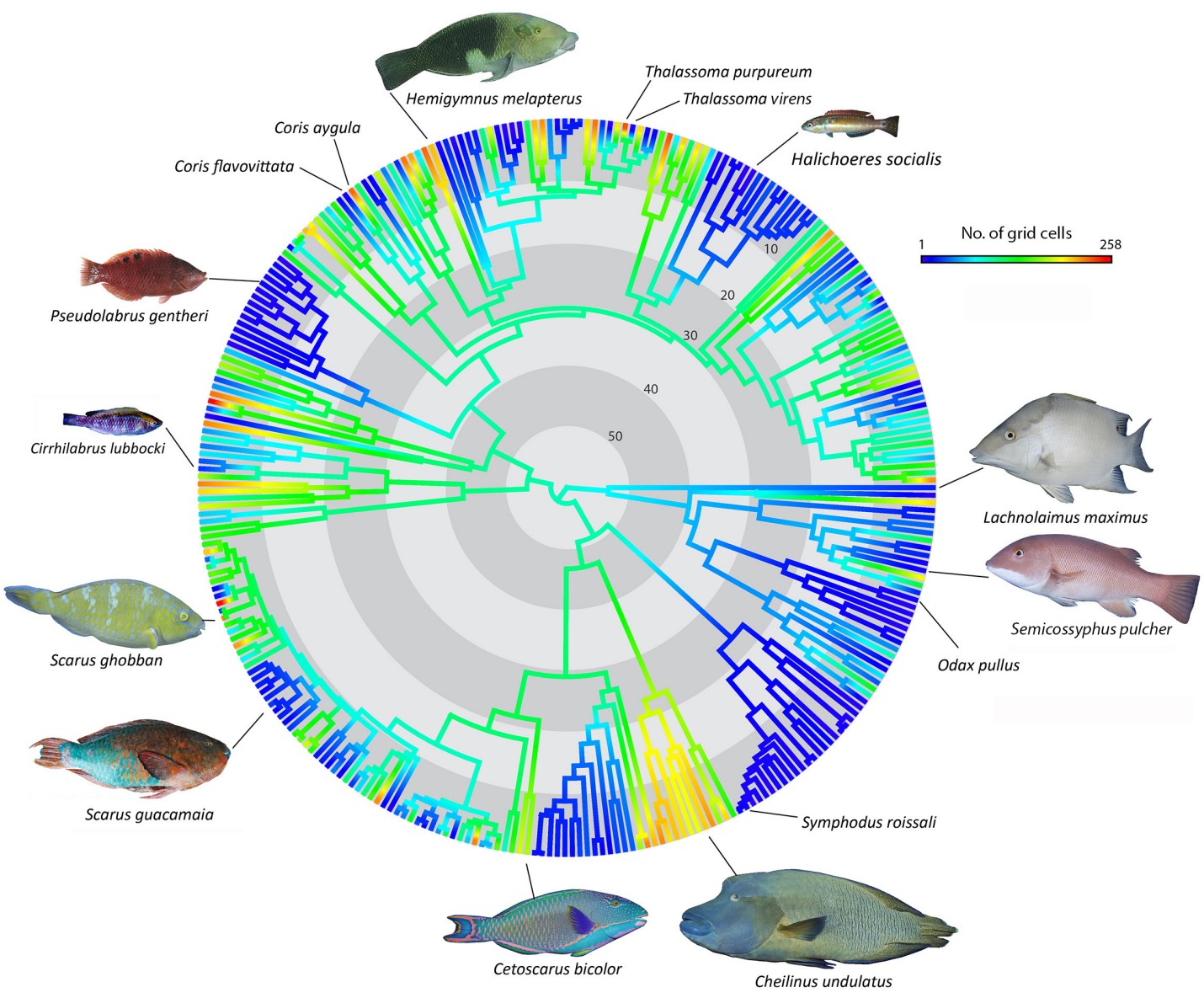



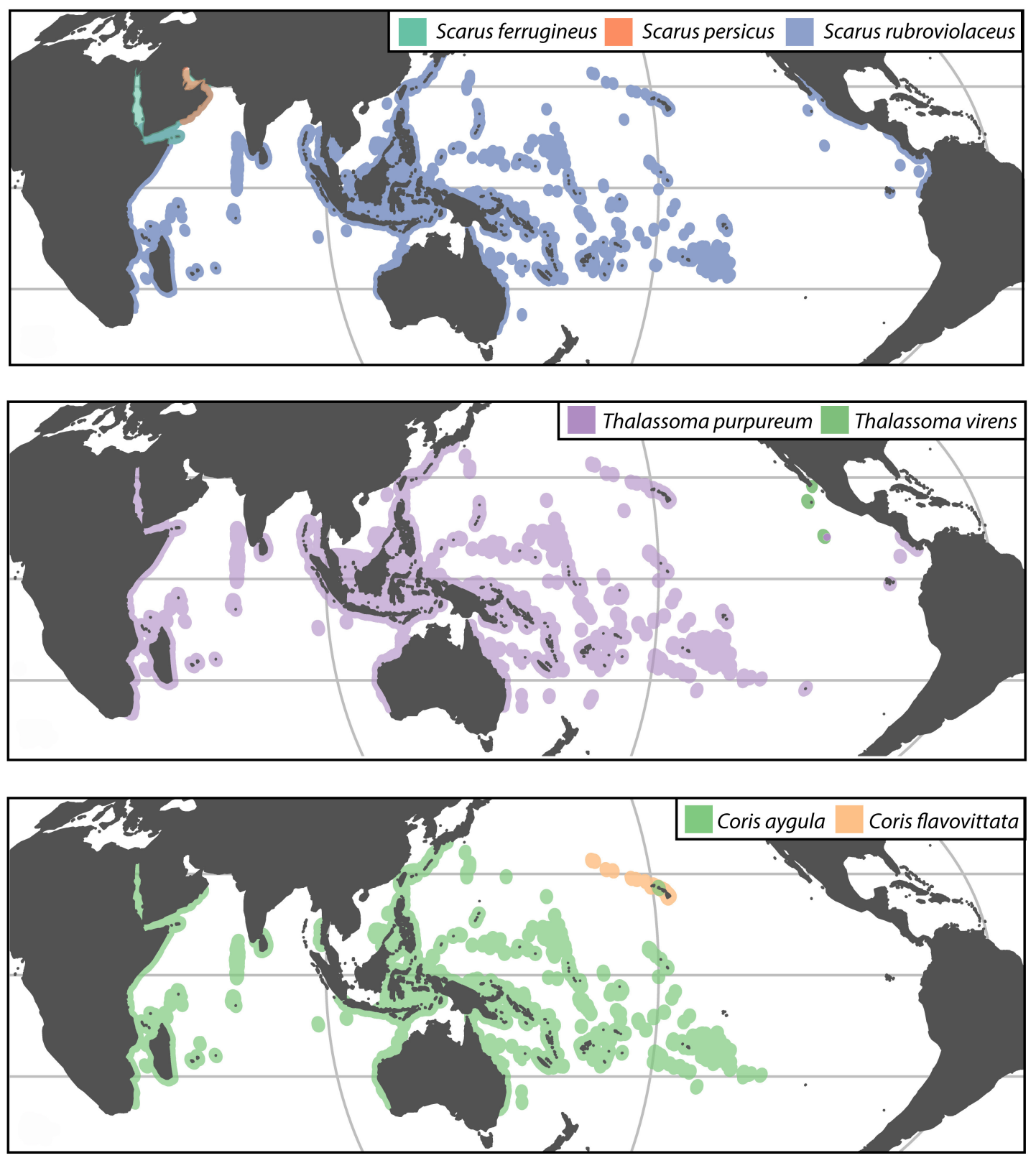
Figure 8
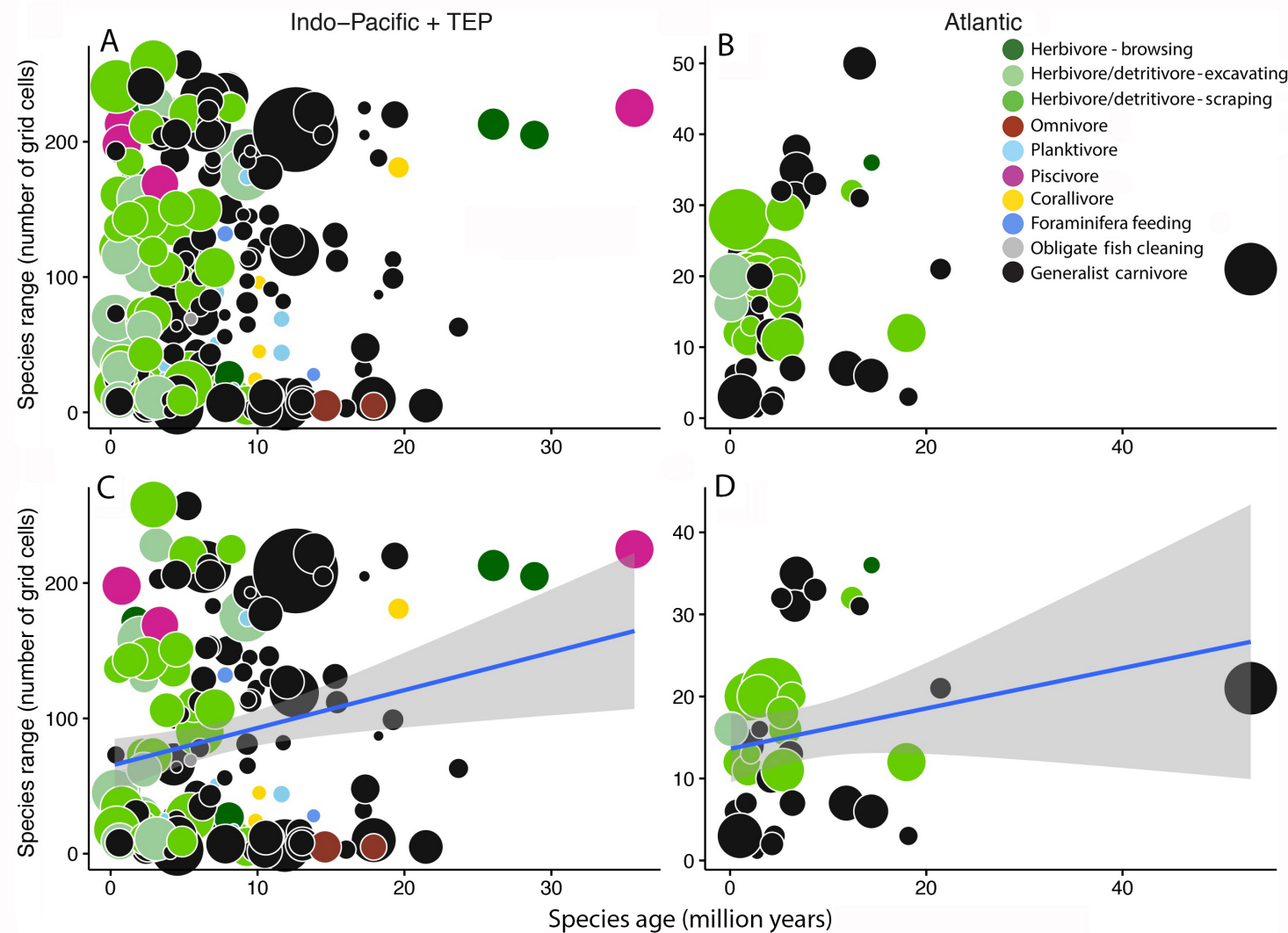

1530

Species age (million years)

1531

1532

1533

1534

1535

1536

1537

1538

1539

1540

1541

1542

1543 
Figure 9

Labridae
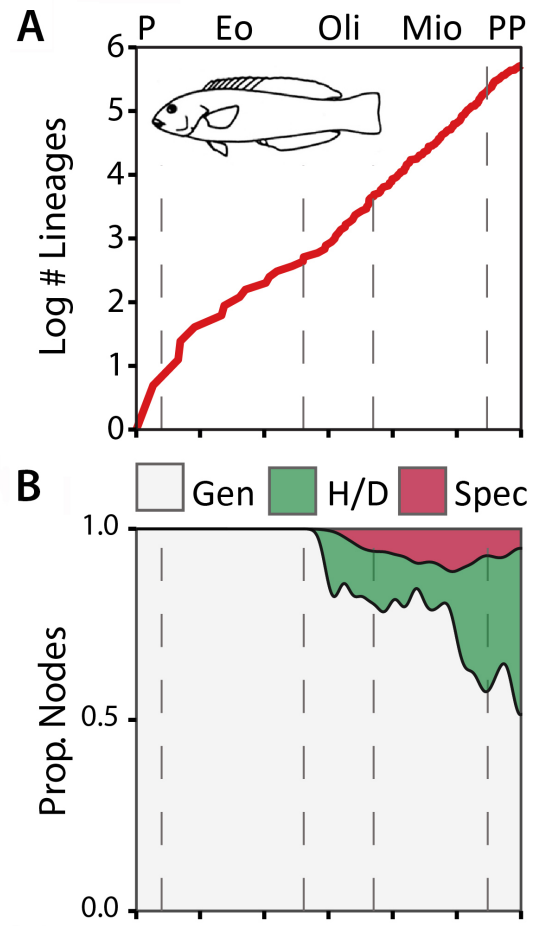

C

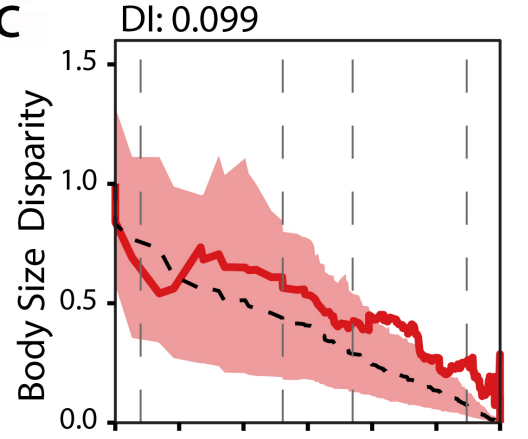

D

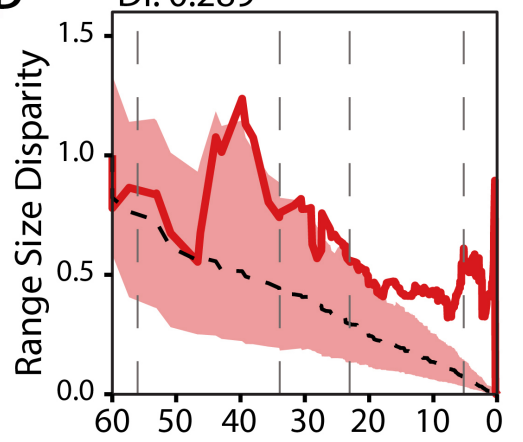

Pomacentridae
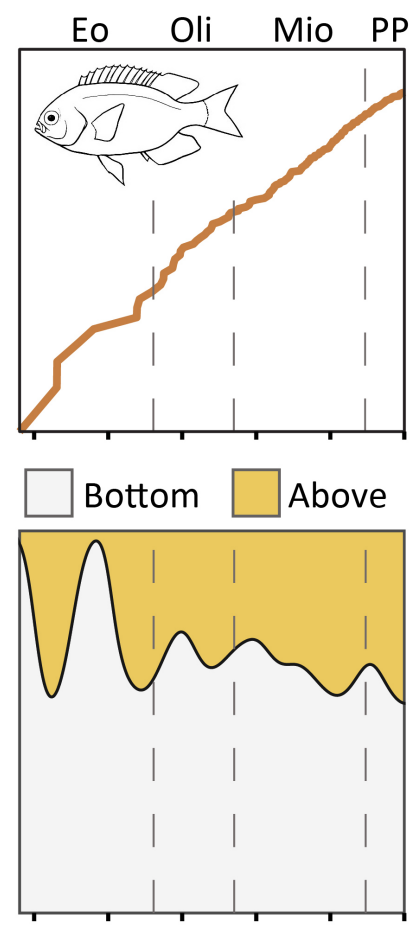

DI: 0.124

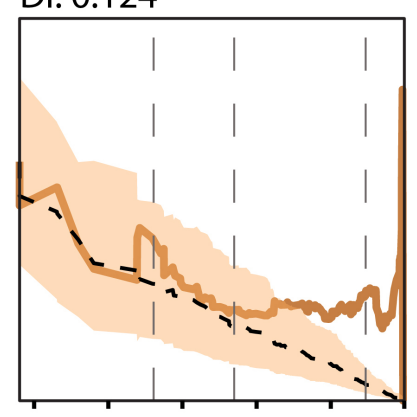

DI: 0.503

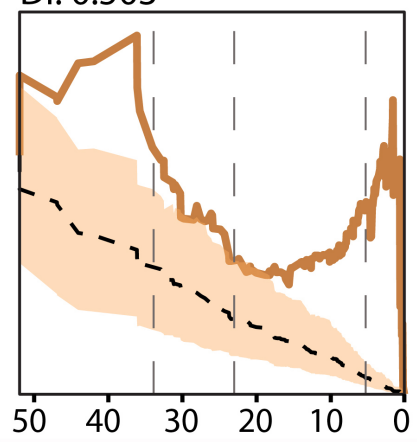

Age (million years ago)
Chaetodontidae
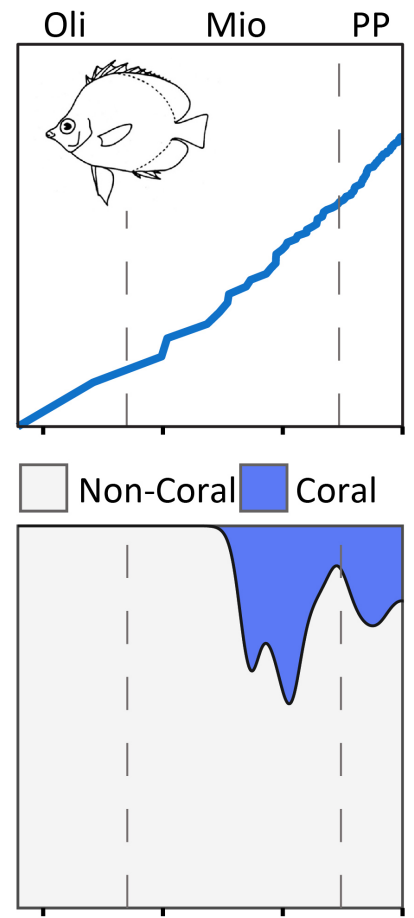

DI: 0.308

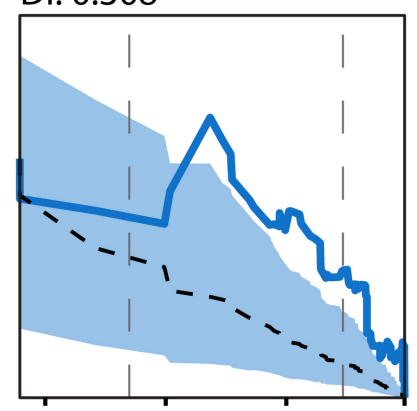

DI: 0.0216

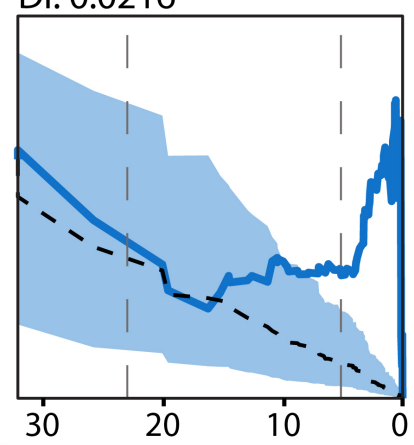


1554

1555
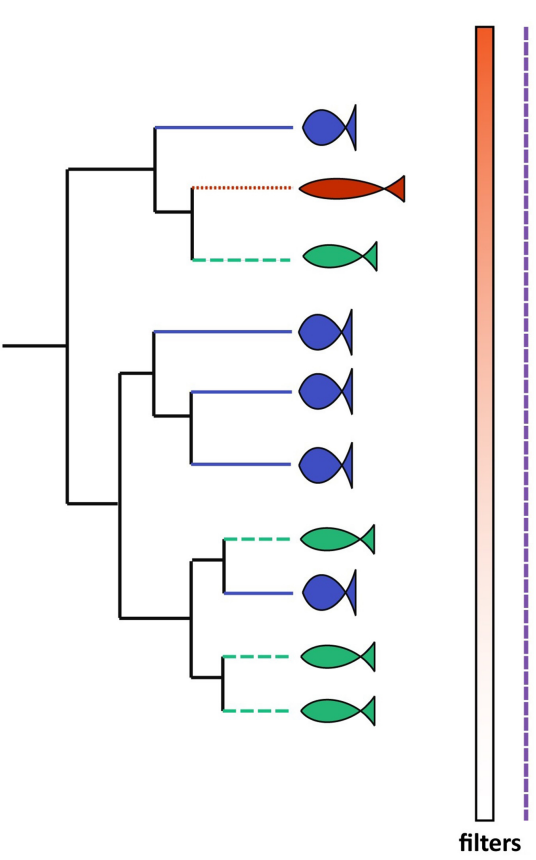

Clustering
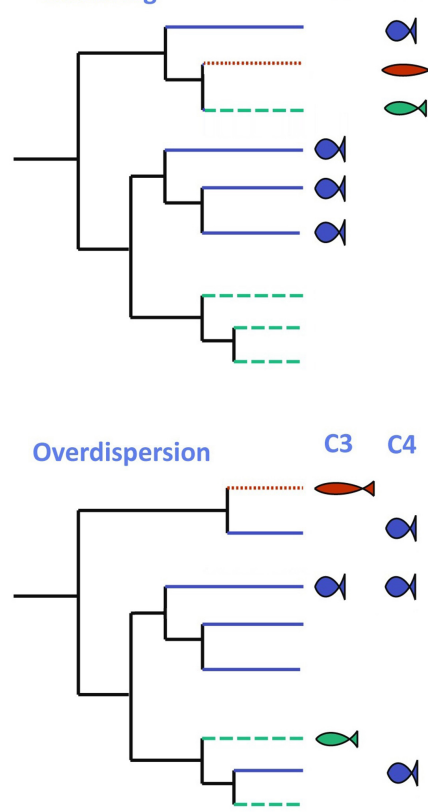

C1 C2 Abundance patterns

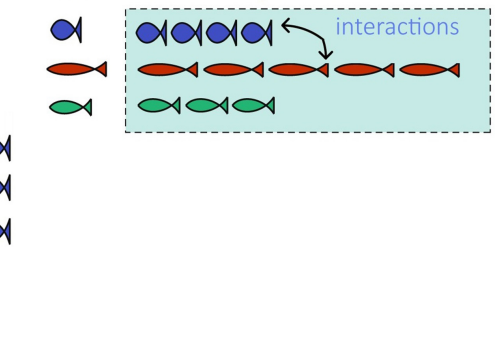

1556 